\title{
An eHealth Diptych: The Impact of Privacy Regulation on Medical Error and Malpractice Litigation
}

Nicolas P. Terry ${ }^{\dagger}$

\section{INTRODUCTION}

Notwithstanding the continuing debate over the future of managed care and the appropriate protections to be included in a Patient's Bill of Rights, the safeguarding of patient privacy and the reduction of medical error have emerged as the dominant health law issues. Displacing even the implications of the advances in genomics from the front and editorial pages of our newspapers, privacy and medical error have left the cozy world of professional journals and political platitudes to demand corrective action.

The issue of data privacy already possessed some serious political credentials before the Clinton administration ushered health privacy to center stage by its promulgation of regulations under the Health Insurance Portability and Accountability Act of 1996 (HIPAA). 1 Public visibility was increased by the Bush administration's very vocal dissatisfaction with the regulations, ${ }^{2}$ followed by its well publicized, though probably temporary, capitulation. ${ }^{3}$ Only recently has medical error resurfaced as an issue of comparable weight attracting public and political concern. ${ }^{4}$ A series of publications by the Institute of Medicine (IOM) have not only highlighted the quality flaws in our current system, but have intensified the debate beyond clichéd calls for action by appending highly concrete suggestions for amelioration of the problem.

This article argues that the forces driving increased privacy and reduced medical error are closely related; that they find common ground in process re-engineering and the adoption of technologies that conceptually, architecturally and operationally will

$\dagger \quad$ Professor of Law and Co-Director, Center for Health Law Studies, Saint Louis University. I am indebted to Jennifer Marsh, J.D. anticipated 2003, for her most able research assistance and editorial skills. Kathleen Casey and Peggy McDermott of our library faculty were indefatigable in tracking down my more obscure requests. Barry Furrow, Joel Goldstein, Jeff. Lewis, Fran Miller and Sidney Watson were particularly generous with their time in commenting on earlier drafts.

(C) 2001 Nicolas P. Terry. All Kights Reserved.

Health Insurance Portability and Accountability Act of 1996, Pub. L No. 104-191, 110 Stat. 1988 (codified as amended scattered in portions of 29 U.S.C., 42 U.S.C. and 18 U.S.C.).

2 See Robert O'Hartow Jr., Protecting Patient Data, WASH. POST, Mar. 23, 2001, at E01

3 Press Release, HHS PRESS OFFICE, Statement by HHS Secretary Tommy G. Thompson Regarding the Patient Privacy Rule, Apr. 12, 2001, available at http://www.hhs.gov/news.

4 See, e.g., Medical Error Reduction Act of 2000, S. 2038, 106th Cong. (2000). 
intersect and frequently combine. ${ }^{5}$ The new and controversial federal medical privacy regulations should be put into perspective and recognized as a relatively minor, albeit laudable, component of a broader thrust to update our delivery system to improve, among other things, the quality of care. Additionally, this article argues that increased privacy regulation will further stimulate emerging eHealth ${ }^{6}$ business models as improved privacy and security accelerate the utilization and acceptability of computer-mediated healthcare delivery.

In addition to exploring the close and dynamic relationship between health privacy and medical error, this article examines how the infrastructure developments and new privacy regulations will more immediately and often unintentionally reshape one of our extant quality assurance systems-malpractice law. In this regard, it examines how traditional substantive malpractice law is already reacting to changes in healthcare technologies, suggesting that aspects of the privacy regulations will have serious, albeit unanticipated, effects on doctrines such as informed consent and, by reducing false positives, the overall level of malpractice-based risk reallocation.

Part II begins with a discussion of the process and technological implications of the federal government's regulation of medical privacy, particularly in terms of its structure and architecture. Part III will examine the role of technology in reducing medical error. The remainder of the article focuses on the more technical legal implications of the interaction between privacy regulation and the drive to reduce error. In this context, Part IV will scrutinize the impact of privacy regulation and eHealth on substantive malpractice law. Part $\mathrm{V}$ will examine the relationship between consent-to-disclosure in privacy regimes and informed consent. Finally, Part VI will discuss the operational or process implications of new privacy and security regimes on malpractice litigation.

\section{BEYOND PRIVACY: ARCHITECTURAL AND QUALITY IMPLICATIONS OF "ADMINISTRATIVE SIMPLIFICATION"}

At first glance, protecting privacy and improving quality seem to implicate diametrically opposed operational imperatives. The protection of privacy suggests a need to decrease the flow of patient-related information, whereas maximizing information and minimizing information costs are key strategies aimed at improving the quality of care. In fact, nothing could be further from the truth. The overall HIPAA-mandated system is driven by a desire to invigorate the flow of medical

5 Some limited intersections have previously been identified. See, e.g., James G. Hodge, Jr. et al., Legal Issues Concerning Electronic Health Information Privacy. Quality, and Liability, 282 JAMA 1466, 1466 (1999).

6 eHealth has been defined in the following terms:

E-health or, as e-commerce analysts term it, e-health space refers to the delivery of health information, diagnosis, treatment and other services or healthcare transactions using information technologies, particularly those utilizing the Web or Internet. The "space" includes such familiar interactions as telemedicine, physician-patient e-mail communications and online prescribing. More recently, however, considerable attention has been paid to what are known as business-to-business transactions between providers, insurers, and other institutions, transactions that impact financing and the confidentiality and security of patient records.

Nicolas P. Terry, Structural and Legal Implications of E-Health, 33 J. HEALTH L. 605, 605 n.1 (2000). See also Gunther Eysenbach, What is e-Health?, 3 J. MED. INTERNET RESEARCH e20 (2001), available at http://www.jmir.org/2001/2/e20/index.htm; Vincenzo Della Mea, What is e-Health (2): The Death of Telemedicine?, 3 J. MED. INTERNET RESEACRH e22 (2001), available at http://www.jmir.org/2001/2/ e22/index.htm. 
information; data protection was appended only to preempt likely provider attempts to externalize the inevitable privacy costs. ${ }^{7}$

The relationship between privacy and quality, however, goes beyond the operational to the architectural. It is not a clean relationship; it is frequently nonlinear while intersections occur at several levels. First, it is true that HIPAA's "Administrative Simplification," which begat our new federal health privacy regulations, was "sold" to the healthcare industry on the basis of its cost-saving architecture. However, on closer examination the improvement of healthcare quality seems to have been an equally strong rationale. Second, the process and technology architecture that will be required to comply with HIPAA - and achieve the promised cost extraction-will lend itself very nicely to the next generation of medical error reducing systems. Third, many of our existing error reducing systems have been ineffective because of provider non-compliance or because our existing systems fail to generate appropriate data. The data architecture and information technology (IT) infrastructure contemplated by HIPAA will likely reinvigorate those systems and their dependent reporting structures. Fourth, consumers will respond positively to improvements in the protection of medical privacy with increased demand for technologically-mediated medicine and online information about healthcare and healthcare providers.

The healthcare industry's attention has been tightly focused on the new HIPAA privacy regulations. ${ }^{8}$ Indubitably, many providers view them as an unwelcome and extremely expensive example of governmental overreaching and overregulation.? Equally, privacy advocates welcome the regulations. 10 Whatever their merits, however, the privacy regulations are merely a means to an end. Furthermore, the privacy regulations are only a relatively minor, albeit costly, component of HIPAA, just as HIPAA's "Administrative Simplification" is only a component of the overall health information architecture.

The journey through the technical world of HIPAA (and an apparently unlimited collection of acronyms) begins with HIPAA's "Administrative Simplification" Subtitle F, wherein we discover that HIPAA was designed "to improve ... the efficiency and effectiveness of the health care system, by encouraging the development of a health information system through the establishment of standards and requirements for the electronic transmission of certain health information." 11

Somewhat buried in the HIPAA statute 12 was a provision re-tasking the National Committee on Vital and Health Statistics (NCVHS) ${ }^{13}$ to become the primary advisory

7 See infra text accompanying note 35

8 Standards for Privacy of Individually Identifiable Health Information, Final Rule, 65 Fed. Reg. 82,462 (Dec. 28,2000 ) (to be codified at 45 C.F.R. $\$ \$ 160,164$ ). The regulation text is available at http://aspe.hhs.gov/admnsimp/final/PvcTxt01.htm.

9 See AM. HOSP. ASS'N, HIPAA: PRIVACY, SECURITY, AND ElECTRONIC TRANSACTIONS STANDARDS, at http://www.aha.org/hipaa/hipaa_home.asp (last visited Nov. 9, 2001) (providing documents related to HIPAA's implementation). However, note the joint letter to the Chairman of the House Ways and Means Committee from the AHA, the Federation of American Hospitals and other hospital groups urging Congress not to delay the electronic transactions standards beyond the October 2002 compliance date. Id.

10 For a friendly yet critical analysis, see Lawrence O. Gostin, National Health Information Privacy, Regulations Under the Health Insurance Portability and Accountability Act, 285 JAMA 3015 (2001).

11 Health Insurance Portability and Accountability Act of 1996, Pub. L No. 104-191, $\$ 261$, 110 Stat. 1988 (1996).

12 Health Insurance Portability and Accountability Act of 1996, Pub. L No. 104-191, § 263, 110 Stat. 1988 (1996).

13 http://ncvhs.hhs.gov/. 
group for health information policy, essentially overseeing the development of the nation's health information systems. Pursuant to this HIPAA mandate, the NCVHS Workgroup first published a concept paper in October 1998,14 followed by an Interim Report in June 2000,15 which sketches the broad model for a National Health Information Infrastructure (NHII) as "the set of technologies, standards, applications, systems, values, and laws that support all facets of individual health, health care, and public health." 16

The rate of progress towards a NHII has attracted negative comments from the President's Information Technology Advisory Committee (PITAC). In its February 2001 report, the Committee noted that, "The U.S. lacks a broadly disseminated and accepted national vision for information technology in health care."17 PITAC singled out the Department of Health and Human Services (DHHS) as failing to "have a clear, strategic vision of the benefit that the department and all of its agencies could receive from information technology research and use of information technology tools." 18

Although progress towards a NHII may not have been as rapid as some would like, NCVHS has made all the right noises about protecting patient privacy and has denied that a NHII is merely an attempt by the government to collect personal health information. ${ }^{19}$ Consistent with the overall thesis of this article, it is quite telling that in listing the benefits of an NHII, NCVHS first makes reference to the reduction of medical error: "Through the use of integrated information technologies, it is hoped that different segments of the medical care system will be able to 'talk' to one another better and faster, and, in the process, dramatically increase diagnostic accuracy and spot potential errors before they injure patients." 20 This linkage has been endorsed by PITAC, with the comment that, "Only information technology can help us take data from records of individual care and make them available for analysis of populations, both for the generation of new epidemiological knowledge

14 NaT'L COMm. ON VITAL aNd HEALTH STATISTICS, NHII WORKGroup ON THE NAT'L HEALTH INFO. INFRASTRUCTURE, ASSURING A HEALTH DIMENSION FOR THE NATIONAL INFORMATION INFRASTRUCTURE (1998), available at http://www.ncvhs.hhs.gov/hii-nii.htm.

15 NAT'L COMM. ON VITAL AND HEALTH STATISTICS, NHII WORKGROUP ON THE NAT'L HEALTH INFO. [NFRASTRUCTURE, INTERIM REP., TOWARD A NATIONAL HEALTH INFORMATION INFRASTRUCTURE (2000) [hereinafter NCVHS INTERIM REP.], available at http://ncvhs.hhs.gov/NHI12kReport.htm.

16 Id. The NCVHS INTERIM REP. continues,

The broad goal of the NHII is to deliver information to individuals-consumers, patients, and professionals-when and where they need it, so they can use this information to make informed decisions about health and health care....

The content of the NHII will be varied and complex. It includes clinical, population, and personal data; practice guidelines; biomedical, health services, and other research findings; and consumer health information. Currently, health information is stored in many locations. The NHIl seeks to connect that information where links are appropriate, authorized by law and patient permissions, and protected by security policies and mechanisms. In effect, the content moves beyond data to information and, ultimately, to knowledge based on analysis and experience.

Id.

17 President's info. Tech. Advisory Comm., Panel on Transforming health Care,

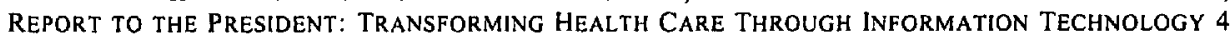
(2001) [hereinafter PITAC REP.], available at http://www.itrd.gov/pubs/pitac/.

$18 \quad$ Id at 8.

19. See NCVHS INTERIM REP., supra note 15.

$20 \mathrm{Id}$. 
and for the generation of prudent health policy."21

The key "Administrative Simplification" component of this future NHII is the enabling of Electronic Data Interchange (EDI) for the healthcare system. Fundamentally, EDI is the electronic exchange of standardized business documents between what are known as "trading partners." 22 The EDI architecture envisioned by the regulations made-or to be made-under HIPAA (hereinafter HIPAA-EDI) requires the "use of national transaction standards when performing these business transactions between organizations electronically [and] . . that all parties using these transactions for healthcare follow the guidelines established by national implementation guides." 23

The HIPAA-EDI model is highly technical,24 but conceptually straightforward. ${ }^{25}$ Those healthcare entities that opt to use EDI will be required to comply with very detailed "Transaction and Code Sets." 26 These data models are generally third party standards ${ }^{27}$ promulgated by organizations such as the American National Standards Institute's (ANSI) Accredited Standards Committee (ASC) X1228 and the National Council for Prescription Drug Programs (NCPDP). ${ }^{29}$ HIPAA-EDI defines its "trading partners" by way of "identifiers" for health plans, individuals, healthcare providers and employers. ${ }^{30}$ When it is fully implemented, ${ }^{31}$ HIPAA-EDI

$2 i \quad$ PITAC REP., supra note 17 , at 2 , noting:

Advances in information technology can provide the foundation for important improvements in health care delivery, such as more cost effective monitoring and follow-up of patients beyond health care centers and dynamic, optimal targeting of specific sectors of the population for special education, screening, and early treatment where necessary. Information technology can also help to provide better feedback loops for connecting providers, policymakers, and patients with late-breaking research and discussions about clinical decisionmaking policy.

22 See generally Jane K. Winn, XML and the Legal Foundations for Electronic Commerce: Making XML Pay: Revising Existing Electronic Payments Law to Accommodate Innovation, 53 SMU L. REV. 1477, 1478 (2000) (discussing the technologies underlying electronic commerce).

23 Siemens Med. SOlutions Health ServS. CORP., HIPAA Overview, at http://www.smed. com/hipaa/overview.pinp (last visited Oct. 26, 2001).

24 For background, see ROY RADA, HIPAA@IT REFERENCE: HEALTH INFORMATION TRANSACTIONS, PRIVACY, AND SECURITY 13-48 (2001).

25 Electronic data interchange (EDI) is the electronic transfer of information, such as electronic media health claims, in a standard format between trading partners. EDI allows entities within the health care system to exchange medical, billing, and other information and to process transactions in a manner which is fast and cost effective. With EDI there is a substantial reduction in handling and processing time compared to paper, and the risk of lost paper documents is eliminated. EDI can eliminate the inefficiencies of handling paper documents, which will significantly reduce administrative burden, lower operating costs, and improve overall data quality.

Id. at 21 .

2645 C.F.R. § $162.1000(2001)$.

27 See D'Arcy Guerin Gue, Transactions and Code Sets: For Geeks Only?, at http://www. hipaadvisory.com/action/tcs/geeksonly.htm (last visited Nov. 1, 2001). "Transactions and Code Sets Standards are data models that have been defined and approved by agreement of the members of various independent organizations that focus on supporting the electronic transfer of Information." $I d$.

28 http://www.x12.org (last visited Nov. 19, 2001). ANSI ASC X12N HIPAA Implementation Guides are available from the Wash. Pub. Co., at http://hipaa.wpc-edi.com/HIPAA_40.asp (last visited Nov. 9, 2001)

29 http://www.ncpdp.org (last visited Nov. 19, 2001).

30 See Security and Electronic Signatures, 63 Fed. Reg. 43,241, 43,243 (proposed Aug. 12, 1998) (to be codified at 45 C.F.R. pt. 142), available at http://aspe.hhs.gov/admnsimp/ nprm/emplist.htm. See also Margret Amatayakul \& Joan Bisterfeldt, HIPAA On The Job: Data Mapping for HIPAA Transactions, J. AM. HEALTH INFO. MGMT. ASS'N., Jul/Aug 2001, at 16. 
will provide for a fully interoperable, standardized system for processing all data exchanges between healthcare entities. ${ }^{32}$

The express "Administrative Simplification" goal of HIPAA and its regulations is the reduction of healthcare industry administrative and transaction costs. These costs, which may account for as much as one-third of the country's annual $\$ 1$ trillion healthcare expenditures, are "backend" administrative costs associated with billing, reimbursement, insurance claims and prescription fulfillment. ${ }^{33}$ HIPAA seeks to eliminate $10 \%$ or more of these costs by moving the industry to fully interoperable systems for healthcare transactions and promoting efficient healthcare markets. ${ }^{34}$

Encouraging and facilitating the relatively free flow of patient information increases healthcare privacy costs. For the HIPAA-EDI system to be credible, effective and fair, HIPAA limited how many of these costs could be externalized to patients. Accordingly, DHHS has had to enter a world that is far more contentious and politically-charged than that of identifiers and code sets. ${ }^{35}$ The Department's work towards assuring security and privacy for medical information has been published as a Notice of Proposed Rule Making (NPRM) for Security and Electronic Signature Standards, ${ }^{36}$ and, after a contentious NPRM period and some anxious months following the change in administration, as the final Standards for Privacy of Individually Identifiable Health Information (PIHI). ${ }^{37}$

31 In addition to Health Plan and Individual ldentifiers, the Pharmacy and Claims Attachments data sets and the final version of the Security standards are still open in late-2001.

32 The shorter-term "translation" of data between entities that will be required explains the inclusion of the somewhat obscure "Health Care Clearinghouse" within the regulations.

Health care clearinghouse means a public or private entity, including a billing service, repricing company, community health management information system or community health information system, and "value-added" networks and switches, that does either of the following functions:

(1) Processes or facilitates the processing of health information received from another entity in a nonstandard format or containing nonstandard data content into standard data elements or a standard transaction.

(2) Receives a standard transaction from another entity and processes or facilitates the processing of health information into nonstandard format or nonstandard data content for the receiving entity.

45 C.F.R. $\$ 160.103$ (2001). For an example of clearinghouse technology, see NaviMedix, at http://www.navimedix.com/ (last visited Nov. 19, 2001).

33 See Guerin Gue, supra note 27 :

Until now, the country's $1500+$ healthcare payers have employed a huge variety of formats and data requirements to handle claims and other transactions. The industry consensus has been that this lack of a single standard has created a national transaction environment that is unwieldy, error-prone, and unnecessarily costly. Adoption of the HIPAA-mandated TCS standards is expected to provide "administrative simplification" to speed up and streamline business processes, reduce errors, and lower costs.

34 Id.

35 Exceptionally, the individual identifier is somewhat controversial. Development of the individual identifier was purposefully delayed until the protections envisioned in the PIHI regulations were published. It is likely that the individual identifier will be the patient's social security number, itself potentially contentious. See CAL CIV. CODE 1785.11.1(f) (West 2001) (limiting use of social security numbers in healthcare situations). See also the Apr. 26, 1993 letter to Hillary Clinton, in her then role as Chairperson, Health Care Reform Task Force, urging that the Social Security Number not be used as the Health Identification Number, available at http://www.epic.org/privacy/medical/ ssn_letter.txt.

36 Security and Electronic Signatures, 63 Fed. Reg. 43,241, 43,243 (proposed Aug. 12, 1998) (to be codificd at 45 C.F.R.,pt. 142). The final regulation likely will deal primarily with security, while electronic signatures likely will be placed in a separate regulation.

37 Standards for Privacy of Individually Identifiable Health Information, Final Rule, 65 Fed. Reg. 82,462 (Dec. 28,2000 ) (codified at 45 C.F.R. $\S \S 160,164$ ). See also U.S. DEP'T HEALTH AND 


\section{A. BASIC HIPAA-PIHI APPLICABILITY}

The core of the PIHI regulations is the restriction or conditioning of disclosure of health information by a broad range of "covered entities" 38 including, for example, health, but not life, insurers. For the purposes of this article's focus on quality of care and malpractice liability, the key group subject to the regulations is certain healthcare providers. These providers, ${ }^{39}$ such as hospitals and physicians, are subject to the regulations if they "transmit any health information in electronic form in connection with a [HIPAA-EDI transaction]." 40 As a result, providers who submit claims or process referral authorizations electronically will be encompassed by the regulations.

The new regulations limit the disclosures affected providers may make of "protected health information" (PHI). 41 PHI includes oral42 or recorded information that "relates to the past, present, or future physical or mental health or condition of an individual" 43 and identifies or could identify the individual. 44 This will bring a patient's medical record, billing record, email communications and a physician's notes within the sphere of protection. Thereafter the provider may only disclose PHI as permitted by the PIHI regulations. ${ }^{45}$

Enforcement of the disclosure rules is accomplished primarily through compliance systems, which require the provider to appoint a "privacy officer" and train its staff, ${ }^{46}$ and through regulatory oversight. ${ }^{47}$ Additionally, the individual whose PHI is at issue (i.e., the patient and, in a few situations, a personal representative) is given certain access and amendment rights which are discussed in detail below. 48 Patients, however, are not given a private right of action for unauthorized disclosures.

\section{B. Relating PiHI to Other Medical Privacy LAW}

Media coverage and industry angst notwithstanding, HIPAA's PIHI did not invent medical privacy law. As the Ninth Circuit has stated, "The constitutionally protected privacy interest in avoiding disclosure of personal matters clearly encompasses medical information and its confidentiality." 49 Federal constitutional protections against state action exist under the Fourth Amendment and the due

Human SERvs., Office for Civ. Rights, StandaRds for Privacy of INDIVIdually IDENTIFIAble HEALTH INFORMATION [hereinafter GUIDANCE/Q\&AS], available at http://www.hhs.gov/ocr/hipaa/ finalmaster.html (last revised July 6, 2001).

$38 \quad 45$ C.F.R. $\$ 164.502(1)(2001)$.

39 Defined in 45 C.F.R. $\$ 160.103(2001)$

4045 C.F.R. $\$ 160.102(2001)$.

41 See 45 C.F.R. $\$ 164.501$ (2001)

42 It is assumed that oral information must be in a tangible form to be subject to the regulation; otherwise it could not be received or created by the provider. The regulation does not seem to require that an oral communication be recorded. This assumption seems consistent with the advice since issued by DHHS, see infra text accompanying footnote 424 .

$43 \quad 45$ C.F.R. $\$ 160.103(2001)$.

$44 \quad 45$ C.F.R. $\$ 164.501(2001)$.

45 45 C.F.R. \$164.502(a) (2001). The various types of disclosure permitted and how they are regulated is discussed infra at text accompanying notes 255 to 278 .

$46 \quad 45$ C.F.R. $\$ 164.530(2001)$.

$47 \quad 45$ C.F.R. $\$ \S 160.300-.312(2001)$.

$48 \quad 45$ C.F.R. $\$ 164.502$ (g) (2001). See infra text accompanying note 393.

49 Norman-Bloodsaw v. Lawrence Berkeley Lab., 135 F.3d 1260, 1269 (9th Cir. 1998) (holding that research institution violated federal privacy rights of clerical and administrative workers who were tested for intimate medical conditions without their knowledge as part of an employee health examination). 
process clauses of the Fifth and Fourteenth Amendments. ${ }^{50}$ Furthermore, some state constitutions provide for even more explicit privacy protections which impact medical information. ${ }^{51}$

Many states already provide robust privacy and security safeguards for medical information. 52 The 1999 Georgetown Health Privacy Project study of state law found that " $[\mathrm{v}]$ irtually every state has some law aimed at the confidentiality of patient health information, but very few states have anything approaching a comprehensive health privacy law."53 In fact, one has to feel some sympathy for the DHHS mandarins given the task of drafting the PIHI regulations. HIPAA-EDI is predicated on national standards and uniformity, suggesting the need for blanket preemption of state laws. However, the EDI-centric limitations of the federal enabling legislation did not permit the draftspersons to reach many of the pro-privacy features of some state laws, features that the drafters could not eschew for both political and philosophical reasons. 54 As a result, the unsatisfactory "more stringent" partial preemption provision in PIHI is likely to befuddle and annoy healthcare institutions with interstate businesses for years into the future. 55 There may be even worse to come as state legislators are prodded by dissatisfied privacy advocates to pass statutes that fill perceived gaps in the PIHI regulations, thereby increasing the number of nonpreempted protections. 56

Obscured amidst the noise of federal regulations, state statutes and at least two generations of conceptually-related uniform laws ${ }^{57}$ are common law protections, specifically the tort action for breach of confidence which is recognized by a growing number of jurisdictions. ${ }^{58}$ Only a few state medical privacy statutes expressly allow

so See also United States v. Westinghouse Elec. Corp., 638 F.2d 570, 580 (3d Cir. 1980) (holding that employee medical records fall within protected zone of privacy); United States $v$. Sutherland, 143 F. Supp. 2d 609,610 (W.D. Va. 2001) (holding that government cannot disclose prescription records without giving patients a chance to object). See generally Roe v. Wade, 410 U.S. $113,152(1973)$ :

The Constitution does not explicitly mention any right of privacy. In a line of decisions, however, going back perhaps as far as Union Pacific $R$. Co. $v$. Botsford, the Court has recognized that a right of personal privacy, or a guarantee of certain areas or zones of privacy, does exist under the Constitution. In varying contexts, the Court or individual Justices have, indeed, found at least the roots of that right in the First Amendment; in the Fourth and Fifth Amendments; in the penumbras of the Bill of Rights; in the Ninth Amendment; or in the concept of liberty guaranteed by the first section of the Fourteenth Amendment (citations omitted).

51 See, e.g., King v. State, 535 S.E.2d 492, 494 (Ga, 2000) (discusssing GA. Const. art. I, § I, para. 1). But see Rollins v. Ulmer, 15 P.3d 749, 750 (Alaska 2001) (finding that the registration requirements of Alaska's medical marijuana law are constitutional).

52 See, e.g., CAL. CIV. CODE $\$ \S 56-56.37$ (West 2001); HAW. REV. STAT. ANN. $\$ 323(\mathrm{c})$ (Michie 2001); MONT. CODE ANN. $\S \S 50-16-501$ to $16-553$ (2001); WASH. REV. CODE ANN. $\S \S$ 70.02.005 to.02.904 (West 2001); WIS. STAT. $\S 146.83$ (2001).

53 Joy Pritts et al., Health Privacy Project, The State of Health Privacy: an Uneven Terrain (A Comprehensive Survey of State Health Privacy StatuTes) 20 (1999) [hereinafter HEAlTH PRIVACY STATE REP.], available at http://www.healthprivacy.org. See also tabular data at 32-34.

54 See, e.g., MASS. GEN. LAWS ANN. ch. $111, \S 70 \mathrm{G}$ (West 2001).

55 45 C.F.R. $\$ \$ 160.201-.205$ (2001).

56 See, e.g., TEX. HEALTH \& SAFETY CODE ANN. § 181 (Vernon 2001) (designed to fill the "one-bite" marketing gap frequently cited by privacy advocates). For detail on marketing rule see infra text accompanying note 234 .

57 UNIFORM HEALTH-CARE INFORMATION ACT (1985), available at hittp://www.law.upenn.edu/ bll/ulc/fnact99/1980s/uhcia85.htm; PROPOSED REVISIONS OF UNIFORM HEALTH CARE INFORMATION ACT (2000), available at http://www.law.upenn.edu/bll/ulc/uhcia/hci0600.htm.

58 See, e.g., Hurvitz v. Hoefflin, 101 Cal. Rptr. 2d 558 (Cal. Ct. App. 2001); Tadlock \& 
for a private right of action. ${ }^{59}$ However, as one federal district court recently noted about the PIHI regulations, "the Standards indicate a strong federal policy to protect the privacy of patient medical records, and they provide guidance to the present case."60

Going further, a recent New York case, Doe v. Community Health Plan-Kaiser Corp. ${ }^{61}$ involved an alleged disclosure of confidential information by a medical records clerk employed by the defendant HMO. The court, after considering state statutory provisions imposing duties of unauthorized non-disclosure on care providers ${ }^{62}$ and HMOs, ${ }^{63}$ concluded: "While a private cause of action may not be predicated on ... these statutes [they] define and impose the scope of the actionable duty of confidentiality which arises between certain health care providers . . . and their patients." 64 It is likely that state and federal privacy rules increasingly will be used as the basis of a private right of action for breach of medical privacy.

\section{BUILDING FOR QUALITY ON THE HIPAA-EDI ARCHITECTURE}

It is within this environment, framed by a fledgling National Health Information Infrastructure, the HIPAA-EDI transactional specifications and the convoluted world of federal and state privacy regulation, that healthcare businesses must design and build their new IT systems. In doing so, providers must respond to two interrelated drivers. First, HIPAA-EDI will require a robust infrastructure that will facilitate the interpretation, processing and storage of standard data sets and linked transactions in a way that integrates institutional legacy systems and allows interoperabillity between systems. Second, this extensive investment in IT will motivate providers to extract additional value from the systems, to provide improvements in the quality of care

Keeney, 101 Cal. Rptr. 2d 916 (Cal. Ct. App. 2000); Anonymous v. CVS Corp., 728 N.Y.S.2d 333 (N.Y. Sup. Ct. 2001); Jeffrey H. v. Imai, Biddle v. Warren Gen. Hosp., 715 N.E.2d 518 (Ohio 1999); McCormick v. England, 494 S.E.2d 431 (S.C. Ct. App. 1997); Berger v. Sonneland, 26 P.3d 257 (Wash. 2001).

59 See, e.g., WIS. STAT. $\$ 146.84$ (c) (2001) ("An individual may bring an action to enjoin any violation of $\S 146.82$ or 146.83 or to compel compliance with $\S 146.82$ or 146.83 and may, in the same action, seek damages as provided in this subsection."). See also CAL. CIV. CODE $\$ 56.35$ (West 2001); HAW. REV. STAT. ANN. $\$ 323$ (c) (Michie 2001).

60 United States v. Sutherland, 143 F. Supp. 2d 609, 612 (W.D. Va. 2001)

61709 N.Y.S.2d 215, 216 (N.Y. App. Div. 2000).

62 Unless the patient waives the privilege, a person authorized to practice medicine, registered professional nursing, licensed practical nursing, dentistry, podiatry or chiropractic shall not be allowed to disclose any information which he acquired in attending a patient in a professional capacity, and which was necessary to enable him to act in that capacity. The relatienship of a physician and patient shall exist between a medical corporation, as defined in article forty-four of the public health law, a professional service corporation organized under article fifteen of the business corporation law to practice medicine, a university faculty practice corporation organized under section fourteen hundred twelve of the not-for-profit corporation law to practice medicine or dentistry, and the patients to whom they respectively render professional medical services.

N.Y. C.P.L.R. § 4504(a) (2001)

63 Unless the patient waives the right of confidentiality, a health maintenance organization or its comprehensive health services plan shall not be allowed to disclose any information which was acquired by such organization or plan in the course of the rendering to a patient of professional services by a person authorized to practice medicine, registered professional nursing, licensed practical nursing, or dentistry, and which was necessary to acquire to enable such person to act in that capacity.

N.Y. PUB. Health LAW $\S 4410(2)$ (2001).

64 Doe, 709 N.Y.S.2d at $217-18$ 
through patient-oriented process re-engineering such as the development of Computerized Patient Record systems (CPR) and to leverage the new architecture by offering innovative eHealth products.

Below, these technologies are discussed more closely in the context of the specific legal issues they impact. ${ }^{65}$ This section, however, will note some of the core technologies, from the CPR to Web-based services that will be constructed on, or in close parallel to, the HIPAA-EDI structure.

It is important to remember that the PIHI regulations apply to "protected health information" 66 which is "created or received" 67 by the institution or individual care provider. HIPAA-EDI neither regulates by reference to a CPR-whether or not comprehensive in form-nor expressly calls for the adoption of CPR systems. Accordingly, in the short term at least, a patient's PHI likely will be spread across many systems and various CPRs. Further, some of a patient's medical records will be in discrete unregulated systems because of quirks in the PIHI regulations' complex definitional structure (i.e., paper records held by the quintessential rural physician who only accepts cash). This article, however, projects somewhat beyond the systems still used by many if not most providers today. Rather, it adopts Gostin's description of patient-based longitudinal health records as "patient-specific records in automated form containing all data relevant to the health of an individual (i.e., clinical, financial and research-oriented information, including diagnostic images) collected over a lifetime." 68 Thus, it is assumed that, prompted by the HIPAA-EDI architecture and other forces discussed herein, providers will adopt cohesive, comprehensive CPR systems. Henceforth, this article uses the somewhat inaccurate singular form for CPR, including within that concept multiple, but interoperable and interlinked CPRs.

If HIPAA-EDI is on its face CPR-agnostic, entities such as the Agency for Healthcare Research and Quality (AHRQ) and CPRI-HOST 69 are prodding the industry firmly in the direction of the longitudinal health record. There is no standardized format for a CPR, although there is broad agreement that such a record would contain, " 1 . Integrated view of patient data, 2. Access to knowledge resources, 3. Physician order entry and clinician data entry, 4. Integrated communications support, and 5. Clinical decision support."70 Courtesy of HIPAA-EDI, we now also know the identifiers and data sets that will populate the CPR and make it truly interoperable, such that medical records data can flow smoothly in from and out to external sources such as a doctor's office, a pharmacy or a payer. ${ }^{71}$

Integrated into these transactional systems will be sophisticated data tracking and analysis tools. These will support the flow of the myriad reports and records

65 For example, consider physician order entry, discussed at text accompanying infra notes 125-34, and the CPR at infra text accompanying notes 373-409.

$66 \quad 45$ C.F.R. $\$ 164.501(2001)$.

6745 C.F.R. $\$ 160.103(2001)$.

68 Lawrence O. Gostin, Health Information Privacy, 80 CORNELL L. REV. 451, 458 (1995) (reference omitted).

69 http://www.cpri-host.org/ (last visited Nov. 13, 2001).

70 Paul C. TANG \& W. Ed Hammond, A Progress Report on Computer-Based Patient Records in the United States, in THE COMPUTER-BASED PATIENT RECORD: AN ESSENTIAL TECHNOLOGY FOR HEALTH CARE 1 (1997). See also COMPUTER-BASEd PATIENT RECORd INST., CPRI WORK GROUP ON CPR DESCRIPTION, COMPUTER-BASED PATIENT RECORD DESCRIPTION OF CONTENT (1996), available at http://www.cpri-host.org/resource/docs/content.html.

71 See, for example, the systems being installed by Perot Systems, at http://www.perotsystems. com (last visited Oct. 31,2001 ). 
required to be submitted by healthcare institutions. ${ }^{72}$ In addition, patients will participate in these systems; ordering everything from their choice of meals when hospitalized, requesting referrals, prescription refills and scheduling outpatient appointments. Patients will also provide feedback to the institution and payers regarding the quality of care they received. ${ }^{73}$ The vision of the PITAC is worthy of note:

Decision-support tools can provide critical links between a current patient's condition and previous clinical studies. Existing systems largely focus on detecting errors at the source, through such methods as range checking, alerts, and reminders, or post-hoc quality monitoring and review. While these types of systems are vital components for improving quality of care, important information is often unavailable or inaccessible because it is spread across multiple information systems and/or organizations with differing systems. This can result in poor coordination of care and increased illness and mortality. The challenge of going beyond these approaches to ones that proactively foster best practices will require efforts in the following areas:

- Expanding the range and granularity of routinely captured data.

- $\quad$ Standardizing terminology.

- Developing robust techniques for incorporating new data types into existing clinical data repositories, e.g., images and patient genotype.

- Organizing and collecting large-scale databases to determine best practices.

- Developing guidelines based on such evidence.

- Implementing guidelines so that they are usable effectively at the point of care, including embedded decision support that is continually updated as new evidence accumulates.

- $\quad$ Reducing the cost and difficulty of integrating applications that reside on heterogeneous technologies. ${ }^{74}$

The critical reader may object that some of the scenarios, technologies and business models discussed in this article have, at most, a quite tenuous link to the PIHI regulations or even to the HIPAA-EDI model. ${ }^{75}$ Patient privacy is a major

72 See, e.g., U.S. DeP'T Commerce \& NAT'L TEleCOMM. AND INFo. AdMin., RePort to CONGRESS: ElECTRONIC SIGNATURES IN GLOBAL AND NATIONAL COMMERCE ACT, SECTION 105(A) (2001) (discussing the effectiveness of electronic mail in the delivery of records), available at http://www.ntia.doc.gov/ntiahome/ntiageneral/esign/105a/esign 105a.htm.

73 See generally Press Release, BLUE CROSS of CAL., Blue Cross of California Announces Restructured Physician Quality Initiatives, July 10, 2001, available at http://www.bluecrossca.com/ aboutus.asp. See also Milt Freudenheim, In a Shift, an H.M.O. Rewards Doctors for Quality Care, N.Y. Times, July 11, 2001, at C1.

74 PITAC REP., supra note 17 , at 6-7.

75 See, e.g., Jeff Mildon \& Todd Cohen, Drivers in the Electronic Medical Records Market. HEALTH MGMT. TECH., May 2001, at 14 (detailing the many reasons behind the adoption of electronic records). 
selling point, however, and the highly visible PIHI protections will boost consumer confidence in technologically-mediated healthcare-notwithstanding that PIHI will apply to only a fraction of them. ${ }^{76}$ With $63 \%$ of American adults now going online, compared to $39 \%$ in 1998,77 the bricks-and-mortar healthcare industry will endeavor not to miss the burgeoning online market. Elsewhere $I$ have argued that "e-Health is premised on a fundamentally new patient experience that is unconstrained by familiar points of entry and structures or traditional channels for delivering information."78 Providers will respond to that fundamental change: they will cease equating eHealth to the narrow concept of telemedicine, and along with the entrepreneurs who survive the dot.com meltdown, will build the next generation of healthcare services. ${ }^{79}$

Providers already embrace new business-to-business (B2B) services such as procurement and related e-marketplaces.80 Business-to-consumer (B2C) eHealth services will rapidly grow beyond vertical portals such as WebMD ${ }^{81}$ and spawn treatment auctions, ${ }^{82}$ group-buying services ${ }^{83}$ and sites that match patients to clinical trials. ${ }^{84}$ The emerging health industry IT architecture will interface with increasingly sophisticated consumer product and Web-service hybrids, such as Web-connected medical monitoring appliances, ${ }^{85}$ Palm-based EKG monitors ${ }^{86}$ or diagnosis-enabled cell phones that locate imperiled patients via Global Positioning Systems (GPS). ${ }^{87}$ These will enable remote diagnosis, monitoring, and even treatment, while soon interfacing with implanted chips that deliver prescription medicines. ${ }^{88}$

Most discussions of HIPAA-EDI, and specifically the PIHI regulations, concentrate on what is prohibited. However, HIPAA-EDI is just as important for what it enables and promotes. While publicly complaining about compliance costs, providers-at least institutional ones-favor the basic HIPAA-EDI structure and

76 For example, very few Web-based medical advice sites will be covered by PIHI.

77 Amy Harmon, Survey About Accountability Online, N.Y. TIMES, July 10, 2001, at C1 (citing a Markle Foundation survey of the American public's views of Internet accountability and regulation).

78 Terry, supra note 6, at 605.

79 See generally FIRST CONSULTING GROUP, WHERE WILL THE ROAD TO E-HEALTH LEAD? TEN E-HEALTH TRENDS 2 (2000) ("condensing" changes in the cHealth market to ten trends), at http://www.fcg.com/knowledge/first_reports.asp.

80 See. e.g., MEdibUY, at http://medibuy.com (last visited Nov. 10, 2001); MEdUNITE, at http://www.medunite.com/ (last visited Nov. 10, 2001).

81 http://www.webmd.com (last visited Nov. 10, 2001).

82 See, e.g., MEDICINE ONLINE, Bid for Surgery, at http://www.medicineonline.com/ bidforsurgery (last visited Nov. 10, 2001).

83 See, e.g., HEALTH MARKET, at http://www.healthmarket.com (last visited Nov. 10, 2001); HEALTH ALLIES, at http://www.healthallies.com (last visited Nov. 10, 2001).

84 See, e.g., ACURIAN, at http://www.acurian.com/ (last visited Nov. 10, 2001); CENTERWATCH. Clinical Trials Listing Service, at http://www.centerwatch.com/ (last visited Nov. 10, 2001). telecare/:

See, for example, Panasonic's Tele Homecare system, at http://www.panasonic.com/

Panasonic created the Tele Homecare system to provide healthcare practitioners with a way to monitor, and provide care and education to patients in their homes. Using telecommunications technology, such as the Internet, the Tele Homecare system allows healthcare providers to communicate with chronically ill patients as frequently as necessary, while costing less than in-home care.

Id. For patient monitoring products, including the "LifeShirt," see also VivoMctrics, at http://www.vivometrics.com/home.html (last visited Nov, 10, 2001). $10,2001)$

86 Sce, for example, the ActiveECG system, at http://www.activecenter.com (last visited Nov.

87 See, for example, the Vitaphone, at http://www.vitaphone.de/index_e.htm (last visited Nov. $10,2001)$.

88 See, e.g., MicroCHIPS, Inc., at http://www.mchips.com/ (last visited Nov. 10, 200I) 
promise of cost reduction. 89 Forward-thinking providers likely will view the HIPAAEDI mandate as an opportunity to re-engineer their systems to feature elaborate data collection and analysis mechanisms that are interoperable with the systems of other healthcare entities and, at their core, feature a highly sophisticated CPR. The remainder of this article examines how these systems and the specifics of our new world of privacy protection will conspire in an effort to reduce medical error and reshape aspects of malpractice litigation.

\section{REDUCING MEDICAL ERROR THROUGH TECHNOLOGY}

As discussed above, protecting patient privacy and reducing medical error are inextricably linked by technological growth and process reform. This linkage is a worldwide phenomenon and occurs at many levels-both philosophical and functional, commercial and technological.90 The technology that directly or indirectly is required by the architecture of HIPAA-EDI will hasten, even jump-start, process reform and the development of the overall healthcare information infrastructure. In addition, it will accelerate the acceptance of technological solutions by healthcare professionals, hastening technologically-mediated quality improvement. As Starr has observed, "Broadly speaking, quality has two dimensions: (1) the objective, technical aspects of care (the accuracy of diagnosis and effectiveness of treatment), and (2) service and patient satisfaction."91 While Starr argues that "[t]he impact of the digital revolution on customer service and patient satisfaction may be equally important," 92 he concedes that "[m]ost of the discussion about IT and quality has focused on the development of outcomes measures for improving the technical dimension of care," while observing that "[n]ew knowledge about outcomes should improve not only clinical judgment but also organizational processes, reducing mistakes and iatrogenic disease."93

\section{A. Medical and Medication Error}

Our contemporary understanding of medical and medication error owes much to

89 See Guerin Gue, supra note 27.

90 See, for example, the Final Report of the National Expert Advisory Group on Safety and Quality in Australian Healthcare (1999) (leading to the formation of the Australian Council for Safety and Quality in Health Care), available at http://www.health.gov.au/hsdd/nhpq/pubs/qualsyn/ neagsyn.htm. See also Press Release, Commonwealth DeP'T Health And Aged Care, Minister Launches Australian Council for Safety and Quality in Health Care, Jan. 21 2000, available at http://www.dhac.gov.au/mediarel/yr2000/mw/mw20003.htm; NAT'L HEALTH PRIORITIES AND QUALITY Branch, COMmonwealth DEP'T HEALTH AND AGED CARE, National Safety and Quality Activities Australian Council for Safety and Quality in Health Care, at http:// www.health.gov.au/hsdd/nhpq/quality/natsafet.htm (last modified Feb. 17, 2000); Ross McL Wilson et al., An Analysis of the Causes of Adverse Events from the Quality in Australian Health Care Study, 170 MED. J. AUST'L. 411 (1999). In a similar time frame, both the Commonwealth and states have moved to increase the level of privacy protection. See, e.g., OFFICE OF THE FED. PRIVACY COMMISSIONER, GuIDELINES ON PRIVACY IN THE PRIVATE HEALTH SECTOR, (2001), available at http://www.privacy.gov.au/publications; Privacy Amendment (Privacy Sector) Bill 2000 (Summary) (amending the Commonwealth Privacy Act 1988), available at http://www.law.gov.au/privacy/ billinfo.html; Health Records Bill 2000/2001 (Victoria), available at http://www.dms.dpc.vic.gov.au/ pdocs/bills/B00756/B007561.html.

27.

91 Paul Starr, Heallh Care Reform and the New Economy, HEALtH AfF., Nov./Dec. 2000, at 23,

92 Id. at 28.

93 Id. 
the legacy of the Harvard Study. 94 The current discourse, however, must be dated to the November 1999 publication by the IOM of To Err Is Human: Building a Safer Health System, ${ }^{95}$ which garnered headlines nationwide. The report is a comprehensive exposition of adverse events and iatrogenic ${ }^{96}$ injuries, particularly those caused by error. To Err Is Human will always be known for its oft-quoted statistic that "at least 44,000 Americans die each year as a result of medical errors," 97 making medical error the eighth leading cause of death, ahead of motor vehicle accidents, breast cancer or AIDS. ${ }^{98}$ The IOM report bracketed the medical error phenomenon by also noting that "the results of the New York Study suggest the number may be as high as 98,000." 99 Not surprisingly, both the methodologies behind these studies and the extrapolations built upon them have already attracted criticisms. 100

Medical and medication errors are, of course, merely distributionally-loaded subsets of the universe of adverse events, while negligent or malpractice-related events are a subset of those medical and medication errors. The IOM report defines its terms as follows:

An error is ... the failure of a planned action to be completed as intended (i.e., error of execution) or the use of a wrong plan to achieve an aim (i.e., error of planning).

An adverse event is an injury caused by medical management rather than the underlying condition of the patient.

An adverse event attributable to error is a "preventable adverse event." Negligent adverse events represent a subset of preventable adverse events that satisfy legal criteria used in determining negligence .... ${ }^{101}$

In addition, the IOM report estimated that medication errors account for over 7,000 deaths annually. ${ }^{102}$ As defined by the National Coordinating Council for Medication Error Reporting and Prevention (NCC MERP) ${ }^{103}$ a medication error is "any preventable event that may cause or lead to inappropriate medication use or patient harm while the medication is in the control of the health care professional,

94 Troyen A. Brennan et al., Incidence of Adverse Events and Negligence in Hospitalized Patients: Results of the Harvard Medical Practice Study J, 324 NEW ENG. J. MED. 370 (1991); Lucian L. Leape et al., The Nature of Adverse Events in Hospitalized Patients: Results of the Harvard Medical Practice Study II, 324 NEW ENG. J. MED. 377 (1991).

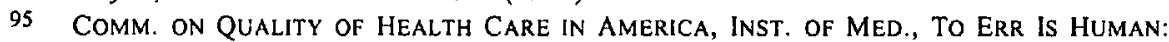
BUILDING A SAFER HEALTH SYSTEM (Linda Kohn et al., eds. 1999) [hereinafter TO ERR IS HUMAN].

96 Induced inadvertently by the medical treatment or procedures or activity of a physician. Originally applied to disorders induced in the patient by autosuggestion based on the physician's examination, manner or discussion, the term is now applied to any adverse condition in a patient occurring as the result of treatment by a physician or surgeon, especially to infections acquired by the patient during the course of treatment.

See ON-LINE MEDICAL DICTIONARY, at http://www.graylab.ac.uk/omd/index.html.

97 TO ERR IS HUMAN, supra note 95 , at 1.

98 Id.

99 Id.

100. See, e.g., Rodney A. Hayward \& Timothy P. Hofer, Estimating Hospital Deaths Due to

Medical Errors: Preventability ls in the Eye of the Reviewer, 286 JAMA 415 (2001).

101 TO ERR IS HUMAN, supra note 95 , at 28 (references omitted).

$102 J d$.

103 http://www.nccmerp.org/. 
patient or consumer." 104 According to AHRQ, "Adverse drug events (ADEs) result in more than 770,000 injuries and deaths each year," 105 while medication errors are a "frequent cause" of medication-related adverse events.106 AHRQ's synthesized research suggests that " 28 percent to 95 percent of ADEs can be prevented by reducing medication errors through computerized medication systems" and that "[c]omputerized medication order entry has the potential to prevent an estimated 84 percent of dose, frequency and route errors." 107

Beyond the " 44,000 deaths" sound byte, however, the long-term contribution of To Err Is Human is its emphasis on process-based solutions. Reason explains the core concepts as follows:

The basic premise in the system approach is that humans are fallible and errors are to be expected, even in the best organisations. Errors are seen as consequences rather than causes, having their origins not so much in the perversity of human nature as in "upstream" systemic factors. These include recurrent error traps in the workplace and the organisational processes that give rise to them. Countermeasures are based on the assumption that though we cannot change the human condition, we can change the conditions under which humans work. 108

Leape appropriately cautions us that " $[\mathrm{t}]$ he systems approach is not a substitute for either responsibility or professional judgment." 109 Equally, he is on point with the comment that "Neither the medical paradigm of training, testing, and blaming, nor the legal paradigm of tort redress has succeeded." 110 The sorry sight of the President and Congress wrangling over whether HMOs should be sued in state or federal courts 111 should serve as an apt metaphor for the near bankruptcy of our traditional approaches to improving the quality of care. Process reform is where regulatory energies and investment dollars will be concentrated over the next decade and, increasingly, our concept of process reform will merge with the healthcare industry's growing appetite for information technologies.

104 Such events may be related to professional practice, health care products, procedures and systems, including prescribing; order communications; product labeling, packaging and nomenclature; compounding; dispensing; distribution; administration; education; monitoring; and use.

Id. See also NCC MERP, TAXONOMY OF MEDICATION ERRORS, at http://www.nccmerp.org.

105 Agency for HealthCare Research and Quality, Pub. No. 01-0020, Reducing and

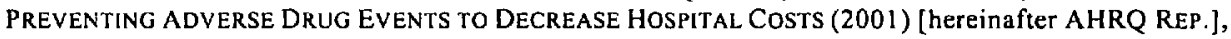
available at http://www.ahrq.gov/qual/aderia/aderia.htm. See also Press Release, U.S. PHARMACOPOEIA, USP Releases First Report on Medication Errors, Dec. 13, 2000, available at http://www.onlinepressroom.net/uspharm (discussing U.S. Pharmacopoeia report, Summary of 1999 Information Submitted to MedMARx ${ }^{S M}$ : A National Database for Hospital Medication Error Reporting).

106 AHRQ REP., supra note 105.

107 Id. See also Assoc. Press, Computers Could Catch Medication Errors, U.S. says, ARIZ. REP., Apr. 12, 2001, at A9.

108 James Reason, Human Error: Models and Management, 320 BRIT. MED. J. 768, 768 (2000).

109 Lucian L. Leape, Foreword: Preventing Medical Accidents: Is "Systems Analysis" the Answer?, 27 AM. J.L. \& MED. 145, 147 (2001).

110 Id. at 148 .

111 See, e.g., Status of Patients 'Rights Bill is Debated, N.Y. TIMEs, at http://www.nytimes.com/ 2001/07/31/politics/31 WIRE-PATIENTS.html (July 31, 2001). See also Robert Pear, Key Lawmaker is Reported Near Deal with Bush on Rights Bill, N.Y. TIMES, July 31, 2001, at A17. 


\section{B. Combating Medical ERroR With Technology}

With considerably less publicity than that generated by To Err Is Human, the IOM subsequently released a report from the same Committee on the Quality of Health Care in America. The 2001 report, Crossing the Quality Chasm: A New Health System for the 2/st Century,"12 noted "the absence of real progress towards restructuring health care systems to address both quality and cost concerns, or toward applying advances in information technology (IT) to improve administrative and clinical processes." 113 This second report devotes an entire chapter to the relationship between technology and quality of care. It notes:

IT has enormous potential to improve the quality of health care .... In the area of safety, there is growing evidence that automated order entry systems can reduce errors in drug prescribing and dosing .... In the area of effectiveness, there is considerable evidence that automated reminder systems improve compliance with clinical practice guidelines . . . . There are many opportunities to use IT to make care more patient-centered, for example, by facilitating access to clinical knowledge through understandable and reliable Web sites and online support groups . . . customized health education ... and the use of clinical decision support systems . . . Both patients and clinicians can benefit from improvements in timeliness through the use of Internet-based communications (i.e., e-visits, telemedicine) and immediate access to automated clinical information, diagnostic tests, and treatment results. . . . Clinical decision support systems have been shown to improve efficiency by reducing redundant laboratory tests. Finally, Internet-based health communication can enhance equity by providing a broader array of options for interacting with clinicians .... 114

Fueled by technological innovation, even the most traditional practice will not be impervious to this revolution. All physicians will interface with sophisticated new systems designed both to reduce "backend" administrative tasks and to positively influence the quality of medical care. Even in traditional practice space, technology and quality assurance will turn out to be intertwined: technology will become an increasingly important component of risk management and quality assurance programs, and will be used to proactively target medical error.

While legislative 115 and regulatory 116 responses increasing the use of technology are likely, and public opinion fuelled by studies such as To Err Is Human will promote reform, most of the immediate pressure to increase technologically advanced medical error reducing systems likely will come from accreditation agencies. The Joint Commission on Accreditation of Healthcare Organizations (JCAHO) has made

112 COMM. ON QUaLity OF HEalTh CARE IN AMERICA, INST. OF MED, CROSSING THE QUALITY CHASM: A NEW HEALTH SYSTEM FOR THE 21 ST CENTURY (2001).

$113 \mathrm{Id}$. at 3.

114 Id. at $175-76$.

115 Press Release, SEN. COMM. ON AGING, Craig Says Computerized Prescription Technology Saves Lives, May 3, 2001, available at http://aging.senate.gov/nr010503.htm.

116 FOOD AND DRUG ADMIN., FinAl SUMmARY OF FOOD AND DRUG ADMINISTRATION ACTION ITEMS-DOING WHAT COUNTS FOR PATIENT SAFETY: FEDERAL ACTIONS TO REDUCE MEDICAL. ERRORS AND THEIR IMPACT (2001) [hereinafter DOING WHAT COUNTS], available at http://www.fda.gov/cder/drug/MedErrors/patientsafety.htm. 
important revisions to its standards that became effective on July 1, 2001. Aimed specifically at adverse events and medical error, the revisions underscore the Joint Commission's requirements as to process engineering and error reporting. 117 Revisions that will implicate technology-based approaches include increasing reporting and proactive risk-reducing systems. ${ }^{118}$ The Management of Information Chapter has been revised to include requirements that will lead to more databasedriven risk management and error reduction systems, ${ }^{119}$ and improvements in the institution's knowledge-base systems. ${ }^{120}$

Together these various initiatives give rise to three overlapping sets of technologies that will tend to reduce medical and medication error. They may be loosely identified as Proactive, Interactive and Informational.

\section{Proactive and Order Systems}

Proactive systems will be the first to appear in quantity, and mass adoption is likely to be rapid. The average physician likely will observe this phenomenon in increased automation of medication, such as automated interaction alerts ${ }^{121}$ and other systems. ${ }^{122}$ Electronic prescribing interfaces increasingly will neutralize the dangers ${ }^{123}$ associated with physicians' notoriously illegible handwriting. ${ }^{24}$ These computerized medication order entry or physician order entry (POE) systems ${ }^{125}$ will also flag objective indications of potential error.126 For example, the systems will check for drug interactions, and require positive identification of both patient and drug at the time of administration ${ }^{127}$ using bar-code or biometric technologies. ${ }^{128}$ The

117 JOINT COMM'N ON ACCREDITATION OF HEALTHCARE ORGANIZATIONS, REVISIONS TO JOINT COMMISSION STANDARDS IN SUPPORT OF PATIENT SAFETY AND MEDICAL/HEALTH CARE ERROR REDUCTION (2001) [hereinafter JCAHO REVISED STANDARDS], available at http://www.jcaho.org/standard/fr_ptsafety.html.

118 These are primarily contained in the Leadership Chapter revisions.

119 JCAHO REVISED STANDARDS, supra note 117, at I.M.8.

120 Id. at I.M.9.

121 See, e.g., David W. Bates et al., Effect of Computerized Physician Order Entry and a Team Intervention on Prevention of Serious Medication Errors, 280 JAMA 1311 (1998).

122 Donna Tapellini, A Wireless Doctor is in the House, WIRED NEWS, at ht:p://www.wired.com/news/technology/0,1282,40560,00.html (Dec. 7, 2000).

123 See, e.g., JCAHO, Medication Errors Related to Potentially Dangerous Abbreviations, SENTINEL EVENT ALERT, Sept. 2001, available at http:/www.jcaho.org/edu_pub/sealert/sea23.html.

124 See, e.g., Theresa Agovino, Digital Rx for Doctors' Bad Handwriting, AKRON BEACON J., June 25, 2001, available at http://www.ohio.com/all/2001/June/25/bizdocs/029130.htm; Editorial, Writing a Medical Wrong, S.F. CHRON., Oct. 10, 2000, at A24. Non-technological approaches to dealing with this issue, such as calligraphy and handwriting courses for doctors, are also being tried. See Janet Wells, Rx for Doctors with

Poor Handwriting, S.F. CHRON., July 1, 2001, at A15.

125 AHRQ REP., supra note 105.

126 Automated dispensing systems are drug storage devices or cabinets that electronically dispense medications in a controlled fashion and track medication use. Their principal advantage lies in permitting nurses to obtain medications for inpatients at the point of use. Most systems require user identifiers and passwords, and internal electronic devices track nurses accessing the system, track the patients for whom medications are administered, and provide usage data to the hospital's financial office for the patients' bills.

See Agency for HealthCare Research and Quality, Pub. No. 01-E057, MaKing Health CaRe SAFER: A Critical Analysis of PATIEnt SAfETy Practices ch. 11 (2001), available at http://www.ahrq.gov/clinic/ptsafety.

127 See, for example, the MEDSTATION System 2000/Rx System 2000, at http://www.pyxis.com/products/medstation2000.asp (last visited Nov. 21, 2001).

128 See SIEMENS MED. SOluTiONS HEALTH SERVS. CORP., Siemens Medication Management Solution: Improving Medication Safety, at http://www.smed.com/solutions/products/medmanagement/ 
adoption of this last technology has been set as a priority by the Food and Drug Administration (FDA). 129

Many of these functions will migrate from the bedside cart to handheld devices (predominantly those using the Palm operating system) ${ }^{130}$ that will more frequently be mandated by the credentialing institution. ${ }^{131}$ The modern, highly portable proactive device may perhaps be best appreciated from the marketing words of one technology supplier:

- Slip your PDA [personal digital assistant] out of your pocket.

- Instantly access your patient's drug benefit plan and history.

- Verify patient eligibility and formulary information with the tap of a stylus.

- Check potential drug interactions with other drugs the patient is taking.

- Transmit accurate prescriptions to the patient's pharmacy of choice instantly.

- All without valuable time spent by your staff on the phone.

- $\quad$ All with only one electronic prescribing system for all of your patients. ${ }^{132}$

Increasingly robust data sets will flow into these devices. For example, the existing FDA MedWatch site provides an Internet gateway for adverse event and clinical safety reporting about over-the-counter drugs, biologics, dietary supplements and medical devices. 133 This data will be available on the ePocrates system that provides point-of-care information for the most commonly prescribed medications, including specific dosing and drug interaction warnings. ${ }^{34}$

\section{Interactive, Surveillance and Expert Systems}

Initially, computer monitoring or surveillance systems 135 -essentially smart supplements to familiar models such as chart review-will define the interactive structure installed by healthcare institutions. These systems monitor objective indicia, such as change in heart or respiratory rates, and assess them by reference to patient-specific information contained in the CPR, such as dosage and patient

index.php (last visited Nov. 15, 2001). See also Susan Lundine, Hospital Software Tracks Down Prescription Info., ORLANDO BUS. J., Apr. 27, 2001, available at http://orlando.bcentral.com/orlando/ stories $/ 2001 / 04 / 30 /$ newscolumn $2 . \mathrm{html}$.

129 See DoIng What CoUnTs, supra note 116. On December 3, 2001 the FDA announced that it would develop a proposed rule requiring bar codes on all prescription drug labels. See FDA: Bar Code Requirement for Drugs Planned as Part of Agency Focus on Patient Safety, 6 Health Care Daily Rep. (BNA) 232 (Dec. 5, 2001).

130 See, e.g., Milt Freudenheim, Digital Doctoring, N.Y. TIMES, Jan, 8, 2001, at Cl.

131 In no large part because of accreditation pressures. See supra text accompanying note 117.

132 RXHUB.NET, at http://www.rxhub.org/sub/physician.html (last visited Nov. 14, 2001). See also PEPID 2001, Portable Emergency and Primary Care Information Database, at http://www.pepid.com/ (last visited Nov, 14, 2001).

133 http://www.fda.gov/medwatch/ (last visited Nov. 14, 2001).

134 Press Release, EPOCRATES, FDA MedWatch Partners with ePocrates to Send Out Drug Safety Alerts, July 17,2001, available at http://www.epocrates.com/headlines/pressreleases.cfm.

135 This terminology is used apparently interchangeably by AHRQ. See AHRQ REP., supra note 105 . 
weight. ${ }^{136}$ These interactive surveillance systems are architecture dependent and closely related to privacy and security impacted or driven technologies.

Surveillance systems will only get smarter. As noted by the IOM, "with increasing use and development of artificial intelligence systems, computer-based patient records may be expected to become interactive, providing diagnostic assistance and even treatment recommendations."137 First, the range and sources of data they process will begin to include normative data such as clinical guidelines. Second, their outputs will become increasingly evaluative. Information technologies already improve clinician access to all forms of treatment-related information. Fully interactive systems will exploit the logical intersection of diagnostic databases, ${ }^{138}$ practice guidelines and the specific electronic patient record within "expert systems."139 Such expert systems will feature real-time quality assurance monitoring of the quality of care received by patients and will both aid and, in extremis, override arguably more frail traditional human systems. 140 Obviously, such systems themselves create difficult issues, including risk-reallocation ${ }^{141}$ and device regulation, and impact our understanding of unlicensed practice..$^{142}$

\section{Information and Reporting Systems}

Beyond providing the operational infrastructure for proactive and interactive systems, the new healthcare technology infrastructure will have a dramatic effect on the quantity, flow and utility of information about medical and medication errors. Immediately, the new health information infrastructure will increase the robustness of peer-review-based reporting of adverse events to risk managers, disciplinary agencies and, increasingly, to patients and prospective patients. ${ }^{143}$ Computer surveillance

136 Id

137 INST. OF MED., THE COMPUTER-BASEd PATIENT RECORD: AN ESSENTIAL TECHNOLOGy For Health CARE 179 (1991) [hereinafter COMPUTER-Based PATIENT ReCORD].

138 See, for example, Thomson MICROMEDEX's UltiMedex Suite, at http:/www. micromedex.com/products/healthcare (last visited Nov. 14, 2001); MEDITECH's Patient Care System, at http://www.meditech.com/Main/Products.htm (last visited Nov. 14, 2001).

139 See, for example, the listing of medical expert systems, at http://www.computer.privateweb. at/judith/name_3.htm (last visited Nov. 14, 2001).

140 See, e.g., POEMS, Post Operative Expert Medical System, at http:/www.cbl.leeds.ac.uk/ sawar/projects/poems/overview (last visited Nov. 14, 2001).

141 See generally Nicolas Terry, When the "Machine That Goes 'Ping "' Causes Harm: Default Torts Rules and Technologically-Mediated Health Care Injuries, 46 ST. LouIS U. L.J. (forthcoming March 2002).

142 [T]he interaction of such "smart" systems with computer-based patient records will also raise a host of legal and policy issues... . Among them will be allocation of responsibility (and liability) for errors in the artificial intelligence system, whether caused by faulty hardware, faulty software, or error in the system's medical rules. The more advanced such systems become, the more questions they will generate about the practice of medicine and whether nonphysicians can use these systems to diagnose and treat patients without physician involvement. In addition, systems that can diagnose or treat patients without intervening professional involvement may be classified and regulated as medical devices under food and drug laws. Finally, these "smart" systems can be expected to lead to a redefinition of the physician's role, as they begin to perform Id. at 179 . functions that formerly only a physician could perform.

143 See William M. Sage, Regulating Through Information: Disclosure Laws and American Healthcare, 99 COLUM. L. REV. 1701,1777 (1999):

In the last few years, however, synergies between continuing demand for cost-containment and availability of new information technologies have launched an "information revolution" among health care providers and care management 
systems will increase the quality of this information, particularly outcome-based data, and will lead to an overall reversal of the trend of underreporting of adverse events.

The new technologies will also encourage the growth of hospital knowledge bases. Although the establishment of such knowledge bases is not new, the increasing standardization that flows from HIPAA-EDI will accelerate the trend toward interoperability between the knowledge bases at different institutions. Analysis required under the JCAHO Sentinel Events policyl44 can be more sophisticated given the new technologies, thus increasing the quality of information fed into the Sentinel Event Database. This is consistent with the July 2001 JCAHO revisions that now include "successful practices" in the list of resources to be included in an institution's knowledge base. ${ }^{145}$ A "successful practice," something of an inverted Sentinel Event, is related to the "Best Practices" being developed by the Accelerating Change Today (ACT) ${ }^{146}$ collaboration of the National Coalition on Health Care ${ }^{147}$ and the Institute for Healthcare Improvement. 148 The coalition has published a series of success stories, ${ }^{149}$ and the American Hospital Association has published "Successful Safety Practices" culled from member activities. ${ }^{150}$ Finally, JCAHO itself publishes a "Sentinel Event Alert" newsletter that combines error data and successful ameliorating practices. 151

Similarly, there will be increased use of de-identified information culled from all these systems. For example, AHRQ's Healthcare Cost and Utilization Project (HCUP) ${ }^{152}$ is designed to create standardized, multi-state health databases that can be used to perform comparative analysis on variations in medical practice and the effectiveness of medical technology and treatments. ${ }^{153}$

organizations directed at performance improvement. In addition, health care purchasers have begun to appreciate the effect that shared information has on performance. Corporate benefits departments are often active partners with managed care organizations in quality assessment and improvement activities, rather than merely serving as information conduits for individual enrollees. In other words, external reporting of information is explicitly linked to internal, often collaborative, analysis (footnotes omitted).

One of Sage's conclusions includes the observation, "Of all possible uses of disclosure, the performance rationale is most likely to create meaningful change in the health care system, but starts from a very different premise-ends-forcing oversight rather than consumer sovereignty." Id. at 1826.

144 JoInt COMM'N ON ACCREDITATION OF HEALTHCARE ORganizations, SENTINEL Event POLICY AND PROCEDURES, available al http://jcprdwl.jcaho.org/sentinel/se_pp.html (last revised June 2, 2000). A sentinel event "is an unexpected occurrence involving death or serious physical or psychological injury, or the risk thereof." $i d$.

145 JCAHO REVISED STANDARDS, supra note 117, at I.M. 9.

146 See NAT'L COALITION ON HEALTH CARE, Accelerating Change Today (A.C.T.)-For America's Health, at http://www.americashealth.org/act_initiative.html (last visited Nov. 16, 2001).

147 http://www.nchc.org/ (last visited Nov, 16, 2001).

148 http://www.ihi.org/ (last visited Nov. 16, 2001).

149 NAT'L COALITION ON HEALTH CARE \& INST. FOR HEALTHCARE IMPROVEMENT, REDUCING MEdICAL ERRORS AND IMPROVING PATIENT SAFETY: SUCCESS STORIES FROM THE FRONT LINES OF MEDICINE (2000), available at http://www.nchc.org/releases/medical_release_2-22.htm.

150 AM. HEALTH ASS'N, Successful Safety Practices, at http://www.aha.org/medicationsafety/ SuccessfulP ractices.asp (last visited Nov 17, 2001).

151 See, e.g, JCAHO, Look-Alike, Sound-Alike Drug Names, SENTINEL EVENT ALERT, May 2001, available at http://jcprdw1.jcaho.org/edu_pub/sealert/sea 19.html (last visited Nov. 17, 2001).

152 AgENCY FOR HEALTHCARE RESEARCH AND QUALITY, The Healthcare Cost and Utilization Project, at http://www.ahrq.gov/data/hcup/hcup-pkt.htm (last visited Nov. 19, 2001).

153 For example, the Kids' Inpatient Database (KID) contains data from approximately 1.9 million hospital discharges for children, at http://www.ahrq.gov/data/hcup/hcupkid.htm (last visited Nov. 19, 2001). 
The Health Care Quality Improvement Act of 1986 (HCQIA) ${ }^{154}$ took a twopronged approach to peer-review-based quality improvement. First, it promoted good faith professional review activities by granting immunity to those engaged in certain forms of peer-review. 155 Second, it provided for certain instances of mandatory reporting of data likely coupled to adverse events or medical error to a National Practitioner Data Bank (NPDB).156 Under HCQIA, peer-review entities taking adverse actions must report to state licensure boards. ${ }^{157}$ Insurance companies, provider organizations ${ }^{158}$ and medical licensure boards must report malpractice payments or adverse disciplinary actions directly to the NPDB.159 However, as the Office of Inspector General (OIG) has noted, the level of underreporting is so extreme as to be more properly characterized as non-reporting. 160 Recently, OIG has also been extremely critical of the complaint process for Medicare beneficiaries, the Medicare Utilization Quality Control Peer Review Organization Program (PRO). According to OIG, "[t] he PROs' complaint process is an ineffective safety valve for Medicare beneficiaries. It has improved little over the past 5 years. Its accessibility is questionable. ... It rarely triggers any intervention beyond a letter for substantiated complaints. . . It fails to provide a meaningful response to complainants." 161

Many of the defects in our current reporting systems likely are exacerbated by legal indeterminacies. HCQIA provides a "professional review body" with immunity from damages whenever a "professional review action" is taken. ${ }^{162}$ Questions have

154 Health Care Quality Improvement Act of 1986 Pub. L. No. 99-660, 100 Stat. 3784-3794 (codified as amended at 42 U.S.C. $\$ \S 11101-11152(1994)$ ).

155 Christina A. Graham, Comment, Hide And Seek: Discovery in The Contexto of the State and Federal Peer Review Privileges, 30 CUMB. L. REV. 111 (2000).

$156 \mathrm{http} / / / \mathrm{www} . \mathrm{npdb} . \mathrm{com}$

15742 U.S.C. \$ $11133(1994)$

158 See Am. Dental Ass'n v Shalala, 3 F.3d 445 (D.C. Cir. 1993). The ADA challenged an DHHS regulation which required a "person or entity" to report malpractice settlement payments to a central data bank. $I d$. at 446 . The court held that only entities are required to report, and that the "person" provision violated the HCQIA, under which the regulations were promulgated. $l d$. at 448

15942 U.S.C. $\S \S 11131-11132,11134$ (1994).

160 See U.S. Dep't Health and Human Servs., Offjce of InSPector Gen., Pub. No. OEl-01 -

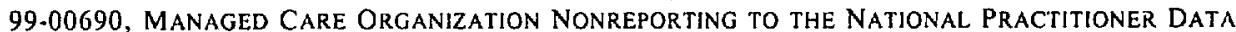
BANK: A SIGNAL FOR BROADER CONCERN ii (2001). Discussing nonreporting by MCOs the OIG report noted:

The two most likely explanations for the low level of reporting:

[1] Limited focus on clinical oversight.

Some managed care organizations devote considerable attention to the quality of care being provided to their enrollees. But we learned that in a health care marketplace that has been changing rapidly, many managed care organizations devote little attention to clinical oversight.

[2] Reliance on downstream entities--hospitals, physician practice groups, and State licensure boards--to conduct quality monitoring of practitioners . .

Id.

161 U.S. Dep'T Health AND Human SERVS., Office INSPECTOR Gen., Pub. No. OEI-01-00-00060,

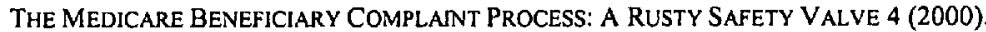

162 If a professional review action . . . of a professional review body meets all the standards specified in section 11112 (a) of this title ... .

(A) the professional review body... shall not be liable in damages under any law of the United States or of any State (or political subdivision thereof) with respect to the action.

42 U.S.C.A. \$11111(a)(1) (West 2001). See also Gabaldoni v. Wash. County Hosp. Ass'n, 250 F.30 255, 260 (4th Cir. 2001) (holding that hospital that had terminated physician's clinical privileges had satisfied the preconditions for HCQIA immunity); No. Colo. Med. Ctr., Inc. v. Nicholas, 2001 WL $705600, * 1$ (Colo. Jun 25,2001 ) (holding that participants in a peer-review of a physician complied 
arisen as to the effect of this provision in the case of a malpractice action brought by a patient against a provider for negligent credentialing. ${ }^{163}$ A related issue concerns the discoverability of documents examined or created during peer-review. While there is a split in authority as to application of federal immunity under HCQIA, most states provide for some protection of peer-review documents, 164 and have begun the process of extending the privilege to medication error reporting. ${ }^{165}$ Notwithstanding, it is abundantly clear that the movement towards disclosure will only increase, ${ }^{166}$ as will the robustness of both criteria and resources available to private ${ }^{167}$ and public 168 accreditation agencies. Equally, the medium for error reporting increasingly will be the Internet. 169

Traditionally, our peer-review and regulatory-based disclosure reporting systems have not involved disclosure of quality of care data-absent deidentification ${ }^{170}$-directly to the consumer. That asymmetry is likely to change, parallel with the increase in the quality and quantity of the data being generated from our new systems. For example, a United States District Court recently held that the federal government's regulations and manual for PRO were invalid under the enabling Peer Review Improvement Act of 1982,171 because they prohibited PROs' disclosure of the disposition of a complaint investigation if that information identified a practitioner who does not consent to disclosure.172 As already noted, the 2001 revisions to the JCAHO standards place particular and additional emphasis on information technologies. ${ }^{173}$ The revised Patient Rights and Organization Ethics

with HCQIA and were immune from contract and tort claims in the state court).

163 Nothing in this chapter shall be construed as affecting in any manner the rights and remedies afforded patients under any provision of Federal or State law to seek redress for any harm or injury suffered as a result of negligent treatment or care by any physician, health care practitioner, or health care entity, or as limiting any defenses or immunities available to any physician, health care practitioner, or health care entity.

42 U.S.C. \&11115(d) (1994). See, e.g., St. Luke's Episcopal Hosp. v. Agbor, 952 S.W.2d 503,.509 (Tex. 1997) (holding that a state statute providing for immunity for provider credentialing decisions applied not only to actions by physicians, but also to patient actions notwithstanding incorporation of HCQIA into Texas statute).

164 See Graham, supra note 155, at 125.

165 See Press Release, U.S. PhaRmaCOPOEIA, USP Granted Legal Protection for Medication Error Reporting in Oklahoma, May 8, 2001, available at http://www.onlinepressroom.net/uspharm.

166 See Sage, supra note 144, at 1704 ("[O]ne regulatory strategy has emerged as a favored approach of disparate constituencies: expanding the amount of information about the health care system circulating among consumers, providers, and voters.").

167 See, e.g., NAT'L COMM. FOR QUALITY ASSURANCE (NCQA), at http://www.ncqa.org (providing both accreditation and performance measurement for MCOs). See generally John K. Iglehart, The National Committee for Quality Assurance, 335 NEw ENG. J. MED. 995, 995 (1996) ("The NCQA accredits managedcare plans that voluntarily request a review of their operations and develops performance measures for plans through the Health Plan Employer Data and Information Set (HEDIS), the most prominent of recent private efforts to develop, collect, standardize, and report measures of plan performance."). See also AM. ACCREDITATION HEALTHCARE/COMMISSION (URAC), at http://www.urac.org.

168 See, e.g., Medicare Program; Establishment of the Medicare+Choice Prograrn, 63 Fed. Reg. 34,968, 34,989 (1998) (incorporating the "Quality Improvement System for Managed Care" (QISMC) standards requiring health plans both to possess quality assessment capabilities and to establish and mect performance improvement goals). See also HCFA, Quality of Care - National Projects, Quality Improvement System for Managed Care (QISMC), al http://www.hefa.gov/quality/3a.htm.

169 See, e.g., MINN. STAT. ANN. \$ $145.61(5)$ (West 2001).

170 See, e.g., 42 U.S.C.A. \$11137 (West 2001).

171 Peer Review Improvement Act of 1982, Pub. L. No.97-248, 96 Stat. 381 (1982) (codified as amended at 42 U.S.C. $\S \S 1320 \mathrm{c}$ to $1320 \mathrm{c}-22$ (1994)).

172 Pub. Citizen, Inc. v. Dep't Health and Human Servs., 151 F. Supp. 2d 64, 66 (D.D.C. 2001).

173 See supra text accompanying notes 117-120. 
Chapter, however, includes the more controversial requirement that, "Patients and, when appropriate, their families are informed about the outcomes of care, including unanticipated outcomes."174

As discussed in Part VI, this direct error reporting reinforced by technology's positive impact on patient-incurred information costs, will have a substantial impact on malpractice litigation: by removing some of the false negatives inherent in our current system, increased error reporting and related quality data will change the level of risk reallocation performed by the torts system.175 Such a disclosure obligation should also effectively increase deterrence once providers know they will have to confront their patients or next-of-kin. In a more haphazard fashion, such information is also likely to filter out to the media and have some marginal effect on consumer choice, while increasing the likelihood of identifying and then rehabilitating the problem doctors. ${ }^{176}$

The hungriest consumers for the medical error data generated by the providers' new information technologies and facilitated by increasing error-reporting requirements will be information intermediaries or "infomediaries." Healthcare is a credence good and the health industry has very little credibility of its own. 177 As a result, consumers will turn to third parties who can deliver to them relevant information without exorbitant sorting costs. Conventional media outlets have already shown an appetite for this type of data. For example, the U.S. News "Hospital Rankings" utilizes both subjective reputation data and objective mortality rates. 178 Beyond the conventional media outlets, the Internet has already proved itself to be the most voracious consumer of information that can influence consumer choice, and increasingly the robust data flowing from providers will find a home on the Web. ${ }^{179}$ For example, the epinion.com service already collates the views of consumers on health and wellness products including OTC drugs, and PatientWise.net enables patients to evaluate their own medical needs in the context of potential providers' experience, complication rates, and mortality rates in similar cases. ${ }^{180}$ The WebMD "Find a Doctor" service is approaching this model from a slightly different direction, providing Web space for doctors and encouraging patients to provide recommendations and other feedback. 181 And the California Healthcare Foundation's PEP-C Report, "What Patients Think of California Hospitals," is to be found in all its detail on the web. 182

Increasingly the ranks of infomediaries will include government regulators. For example, the federal government Web-publishes "Nursing Home Compare,"183 and

174 JCAHO REVISED STANDARDS, supra note 117, at RI.1.2.2.

175 See infra text accompanying note 365.

176 See, e.g., Abagail Zuger, A Program's Goal: Evaluate and Rehabilitate Problem Doctors, N.Y. TIMES, July 3, 2001, at F5 (discussing the Institute for Physician Evaluation).

177 HARRIS INTERACTIVE, Consumer Backlash Against Managed Care and Pharmaceutical Industries-Bottomed out or in Remission?, HEALTH CARE NEWS, May 29, 2001, available at http://www.harrisinteractive.com/news/newsletters_healthcare.asp.

178 U.S. NEWS \& WORLD REP., America's Best Hospitals, July 23, 2001, available at http://www.usnews.com/usnews/nycu/health/hosptl/tophosp.htm. See also SUN. TIMES, Sun. Times Good Hospital Guide, Jan. 14, 2001, at http:/www.sunday-times.co.uk/.

$179 \mathrm{http}: / / \mathrm{www}$.epinions.com/health_beauty/tk_ HP001.1.56 (last visited Nov. 14, 2001).

180 http://www.patientwise.net (last visited Nov, 14, 2001)

$181 \mathrm{http}: / /$ my.webmd.com/find_a_phys/doctor (last visited Nov. 14, 2001).

182 Cal. Healthcare found., What Patients Think of California hospitals (2001), available at http://hospitalguide.chcf.org.

183 U.S. Dep'T HEALTh AND HUMAN SERVS, CTRS: FOR MEdicare \& MEdicaid SERVS., Nursing Home Compare, at http://www.medicare.gov/NHCompare/Home.asp (last visited Nov. 27, 
some states already Web-publish institutional quality rankings, ${ }^{184}$ and physician profiles. ${ }^{185}$ Finally, a system to rate physicians is on the Medicare-reform agenda. 186

Overall, the new IT architecture that is so fundamental to HIPAA-EDI and its privacy and security correlates will dramatically increase the likelihood that information about medical error will be disclosed and comprehensively analyzed. As we build increasingly sophisticated proactive and interactive error-reducing systems on and around the HIPAA-EDI infrastructure, this complex bundle of technologies, and the traction now enjoyed by ever-evolving public and private disclosure systems, will reshape our understanding of medical error and accelerate its amelioration. This linkage between privacy and medical error is less an example of the rule of unintended consequences and more a function of the inherent synergies between HIPAA-EDI transactions and IT-led process reform. In the sections that follow, however, this article observes several intersections between privacy regulation and malpractice law and practice that are less likely to have been intended by the architects of modern health privacy.

\section{THE IMPACT OF PRIVACY REGULATION AND EHEALTH ON SUBSTANTIVE MALPRACTICE LAW}

Privacy regulation and the architecture around which it is developing affects traditional malpractice law in three important areas. First, the disclosure rules and systems that they contemplate will have spill-over effects on informed consent. Second, a robust CPR and patient access to it will impact the malpractice litigation process and the resolution of claims. The third area concerns the likelihood of

2001). Testifying before a Senate Subcommittee, a high-ranking DHHS official recently described this as follows:

The primary purpose of this database is to provide information about the performance of approximately 17,000 Medicare- and Medicaid-certified nursing homes across the country. The database has detailed information gathered from the States that conduct surveys and certify the facilities, including whether any quality deficiencies were found, and how severe thcy were. Furthermore, it has characteristics of the nursing home residents, including the percentage of residents with pressure sores, percentage of residents with urinary incontinence, and more.

Using Technology to Improve Medicare Before the Sen. Comm. on Commerce, Subcomm. on Sci.. Tech. and Space, 107th Cong. 4 (2001) (statement of Tom Scully, Admin., Ctrs. for Medicare \& Medicaid Servs.).

184 See, e.g., MD. HEALTH CARE COMM'N, Maryland Nursing Home Performance Evaluation Guide, at http://209.219.237.235 (last visited Nov. 18, 2001). In England, see NAT'L HEALTH SERV., DEP'T OF HEALTH, NHS Performance Ratings, at http://www.doh.gov.uk/performanceratings/index. html (last visited Nov. 18, 2001).

185 See, e.g., MASs. BOARD OF REgistration IN MED., Massachusetts Board of Registration, Medicine Physician Profile System, at http://www.docboard.org/ma/df/masearch.htm (last visited Nov. 14, 2001); FlA. DeP'T Health AND HuMAN SERVS., Medical Quality Assurance. Practitioner Profiling, at http://www.doh.state.fl.us/mqa/Profiling/index.html (last visited Nov. 14, 2001); VA. BOARD OF MED., VIRGINIA BOARD OF MEDICINE PRACTITIONER INFORMATION, at http://www.vahealthproviders.com/index.asp (last visited Nov. 14, 2001). Such publication is, however, controversial. See, e.g., Sandra G. Boodman, New Tech, Old Politics; Virginia Doctors Block Web Access to Data Available by Phone, Mail, WASH. POST, July 31, 2001 at F01; Tammie Smith, Web Site About Doctors Scrutinized, Disciplinary Data Curbs are Sought, RICHMOND TIMES-DiSPATCH, July 11,2001 , at B3.

186 Julie Appleby, Medicare Overhaul Could Include Ratings: Officials Consider Requiring Hotly Debated Quality Reports on Health Providers, USA TODAY, June 6, 2001, at 1 B (noting the controversial speech by Thomas Scully, head of CMS). In England, government regulators publish information about hygiene in public hospitals. See Lorna Duckworth \& Thomas Bell, Hit Squads Sent in to Clean up Squalid Hospitals, THE INDEPENDENT, Apr. 11, 2001, at 6. 
substantive changes to malpractice law to reflect changes in the practice of medicine brought about by the HIPAA-EDI infrastructure.

The substantive changes to malpractice law that are dealt with in this Part involve three phenomena: the interplay between the utilization of information technologies and the standard of care used in malpractice cases; the manner in which new business models adopted by traditional, bricks-and-mortar healthcare institutions impacts their legal liability; and the difficulties inherent in applying malpractice-like liability models to B2B eHealth entities such as medical advice sites.

It should be added that one action against a healthcare institution or individual care provider that is not discussed in this section is that of breach of confidentiality or other disclosure of private medical information. As discussed above, the PIHI rules do not provide for a private right of action, although it is well within the wit of a plaintiff to construct an action at common law that references federal and state disclosure standards.187 Equally, the plaintiff's bar will swiftly become more conversant in informational wrongs, national and local privacy standards and the myriad of ways that a provider can run afoul of them. Accordingly, it is not unlikely that a breach of privacy allegation will become a standard count in a malpractice complaint, just as duty to warn counts now routinely turn up in products liability actions 188 and as informed consent counts are used to buttress lackluster surgical or medication cases. ${ }^{189}$ Furthermore, it is likely that plaintiffs will use any knowledge they have of provider non-compliance with PIHI regulations-with all the penalty ramifications that brings-as leverage in settlement negotiations in tangentially related malpractice cases.

\section{A. INFORMATION TECHNOLOGIES AND THE STANDARD OF CARE}

As discussed above, 190 the data contained in practice guidelines will increasingly be incorporated in error-reducing expert systems as healthcare entities build interfaces between their knowledge bases and computer surveillance systems. Even prior to such sophisticated integration, practice and clinical guidelines and their fellow travelers, such as evidence-based medicine and clinical pathways, will impact the standard of care.

Driven internationally by the Cochrane Collaboration, 191 and by AHRQ in the United States, 192 evidence-based medicine is "the conscientious, explicit, and judicious use of current best evidence in making decisions about the care of individual patients. The practice of evidence-based medicine means integrating individual clinical expertise with the best available external clinical evidence from systematic research."193 As noted by Sackett:

187 See supra text accompanying notes 59-64.

188 For a broad-ranging discussion of the role and reach of modern warning doctrine, see generally Carlin v. Superior Court, 920 P.2d 1347 (Cal. 1996). See also Nicolas P. Terry, Collapsing Torts, 25 CONN. L. REV. 717, 757 n.197 (1993).

189 See discussion of "bad" cases infra text accompanying note 290.

190 See supra text accompanying note 135.

191 http://www.cochrane.org (last visited Nov. 17, 2001). See also David L. Sackett, Letter, Cochrane Collaboration, 309 BRIT. MED. J. 1514; Mark R. Wormald \& Katherine Oldfield, Evidence Based Medicine, the Cochrane Collaboration, and the CONSORT Statement, 82 BRIT. J. OPHTHALMOL. 597 (1998).

192 AgENCY FOR HEALTHCARE RESEARCH AND QUALITY, Evidence-based Practice, at http://www.ahrq.gov/clinic/epcix.htm (last visited Nov. 17, 2001).

193 David L Sackett et al., Editorial, Evidence Based Medicine: What It is and Whatlt /sn't, 312 BRIT. MED. J. 71, 71 (1996). 
Good doctors use both individual clinical expertise and the best available external evidence, and neither alone is enough. Without clinical expertise, practice risks becoming tyrannised by evidence, for even excellent external evidence may be inapplicable to or inappropriate for an individual patient. Without current best evidence, practice risks becoming rapidly out of date, to the detriment of patients. 194

Evidence-based medicine, whatever its disclaimers and limitations, hints at best practices. Practice or clinical guidelines, however, are quite explicit. Guidelines are generally available on the Web through the National Guideline Clearinghouse, ${ }^{195}$ Medscape, 196 AHRQ, ${ }^{197}$ medical specialty organizations 198 and other content aggregators. 199 When incorporated into more traditional biomedical texts, guidelines are accessible through MEDLINE at the U.S. National Library of Medicine. ${ }^{200}$ The "best practices" normative quality of practice guidelines will be reinforced through the increased availability and dispersal of reports of successful practices both inside a hospital and between institutions. 201 In many cases, institutions will take the initiative and convert such data into explicit norms by adopting clinical pathways. ${ }^{202}$

Unfortunately, as pointed out by Feder, "[t]he development of good guidelines does not ensure their use in practice. Systematic reviews of strategies for changing professional behaviour show that relatively passive methods of disseminating and implementing guidelines-by publication in professional journals or mailing to targeted healthcare professionals-rarely lead to changes in professional behaviour." 203 In this regard Furrow has been critical of institutional infrastructure:

Institutions have been slow to adopt sophisticate information

194 Id.

195 http://www.guideline.gov/index.asp (last visited Nov. 12, 2001).

196 MEDSCAPE, Medscape Multispecialty Practice Guidelines, at http://www.medscape.com/ Home/Topics/multispecialty/directories/dir-MULT.PracticeGuide.html (last visited Nov. 12, 2001).

197 agency for HealthCare Research and Qualtty, Clinical Practice Guidelines Online, at http://www.ahrq.gov/clinic/cpgonline.htm (last visited Nov. 12, 2001).

198 See, e.g., AM. ASS'N CLINICAL ENDOCRINOLOGISTS, Clinical Guidelines Online Index, at http://www.aace.com/clin/guidelines (last visited Nov. 12, 2001); AM. COLL. CARDiologY, Clinical Statements/Guidelines, at http://www.acc.org/clinical/statements.htm (last visited Nov. 12, 2001).

199 See, e.g., MEDEXACT, at http://www.medexact.com (last visited Nov. 18, 2001). MedExact offers centralized, well-designed treatment information on over 600 conditions and disease states. MedExact's treatment information is drawn from the publications of leading medical associations and institutions such as the National Cancer Institute, the National Institutes of Health, and the American Diabetes Association, and are approved by these organizations before being posted at MedExact. MedExact also includes direct links to these organizations' own sites. Id.

$200 \mathrm{http}: / / \mathrm{www} . \mathrm{nlm}$.nih.gov/nlmhome.html (last visited Nov. 19, 2001).

201 See supra text accompanying note 145.

202 A clinical pathway is a tool that sets locally agreed clinical standards, based on the best available evidence, for managing specific groups of patients. The pathway forms part or all of the patient's record and allows the care given by members of the multidisciplinary team, together with the progress and outcome, to be documented.

See Editorial, Peter E. Bundred \& Denise J. Kitchiner, Clinical Pathways: A Practical Tool for Specifying. Evaluating and Improving the Quality of Clinical Practice, 170 MED. J. AUSTL. 54, 54 (1999). See also

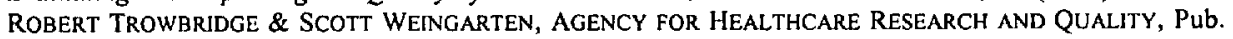
No. 01-E057, Making Health Care Safer: A Critical analysis of Patient Safety Practices, $C h$. 52. Critical Pathways (2001), available at http:/www.ahrq.gov/clinic/ptsafety/chap52.htm.

203 Gene Feder et al, Using Clinical Guidelines, 318 BRIT. MED. J. 728, 728 (1999). 
systems to incorporate patient data and current research. MCOs have been so preoccupied with maintaining market share in a competitive health care economy that they have often deemphasized the goal of quality care. Likewise, many hospitals scrambling to consolidate in regional and local markets have not created management information systems that would better help their medical staffs digest new research information on good practice. 204

It is just this type of IT infrastructure that institutions will build to interface with the HIPAA-EDI architecture. As these kinds of proactive risk-avoidance systems are implemented, the natural correlate is that the normative standard of care expected of all physicians and institutions will evolve to reflect the new information that becomes available. Even prior to the development of expert systems, as doctors increasingly have access to the Internet, they will be able to access the vast amounts of objective, evidence-based data that is available online. 205 As Furrow has concluded, "[ $t]$ he Web is a comfortable tool that is likely to become a source of constant pressure on physicians to improve medical practice."206 .Clearly, medical malpractice opinions have taken careful note of the way in which the dissemination of medical information has changed. For example, one of the leading cases advocating a national standard of care concluded:

Even a cursory analysis of the policy behind the locality doctrine reveals that whatever relevance it has to the practice of medicine in remote rural communities, it has no relevance to medical practice in the District of Columbia. Clearly the nation's capital is not a community isolated from recent advances in the quality of care and treatment of patients. Rather, it is one of the leading medical centers in quality health care. The medical schools in the nation's capital rate as some of the most outstanding schools in the nation. The hospitals in the District not only possess some of the most recent medical technology, but also attract some of the best medical talent from all over the country. Moreover, medical journals from all over the country are available to health care professionals in the District of Columbia, serving to keep practitioners abreast of developments in other communities. In short, the locality rule was designed to protect medical practitioners in rural communities, not practitioners in leading metropolitan centers such as the District of Columbia.

Moreover, any purported disparity between the skills of practitioners in various urban centers has for the most part been eliminated. Unlike the diversified and often limited training that was available a hundred years ago, medical education has been standardized throughout the nation through a system of national accreditation. . . . Moreover, the significant improvements in

204 Barry R. Furrow, Broadcasting Clinical Guidelines on the Internet: Will Physicians Tune In?, 25 AM. J.L. \& MED. 403, 409 (1999) (footnotes omitted).

205 See, e.g., Tyler Chin, Gathering Clinical Evidence Online, AMNEws, Dec. 11, 2000, available at http://www.ama-assn.org/sci-pubs/amnews/pick_00/tesa1 211 .htm.

206 Furrow, supra note 204, at 421. 
transportation and communication over the past hundred years cast further doubt on continued vitality of the doctrine.

In sum, the major underpinnings of the locality doctrine no longer obtain. 207

The parallel is obvious. Driven by the HIPAA-EDI technology infrastructure, pervasive high-speed access to evidence-based data, clinical guidelines and successful practices, emerging knowledge systems will have a far greater impact on the standard of care than nationally accredited medical education and widely available journals did a generation ago. While that latter revolution in information prompted courts to replace the locality rule with a national standard of care, the technologically-mediated knowledge revolution inevitably will lead to the demotion of subjective expert testimony and its eventual replacement with far more objective metrics.

Remarkably, even the admissibility of practice guidelines in malpractice cases remains unsettled and seldom commented on by the courts. One of the few decided cases directly on point is Frakes v. Cardiology Consultants, P.C.. ${ }^{208}$ In Frakes, the defendant's attorney used a table excerpted from a practice guideline while crossexamining the plaintiff's medical expert and during examination of the defendant and a defense witness. The court of appeals affirmed a jury verdict in favor of the defense, placing considerable emphasis on the trial court's discretion. ${ }^{209}$ The plaintiff argued that the table constituted hearsay 210 because it was "prepared by an unknown number of unknown doctors who were not present and were not subject to crossexamination at trial." 211 Addressing this issue, the court held that the table was properly admitted to impeach the defense witness under the state evidence code's learned treatise exception, but that the practice guideline did not fall under the broader hearsay exception for "Market Reports and Commercial Publications."212

While correct on the latter point, the court's narrow "impeachment approach" to the admissibility of practice guidelines is consistent only with the old common law rule, ${ }^{213}$ albeit one retained in the Tennessee code. ${ }^{214}$ Under the Federal Rules of Evidence and those of the overwhelming majority of states codes modeled on them, it seems clear that the modern learned treatise exception would render practice

207 Morrison v. MacNamara, 407 A.2d 555, 562-63 (D.C. 1979) (citations omitted).

2081997 Tenn. App. LEXIS 597, *1 (Tenn. Ct. App. Aug. 29, 1997). See also Rodriguez v. Jackson, 574 P.2d 481 (Ariz. App. 1977); Washington v. Washington Hosp. Ctr., 579 A.2d 177 (D.C. 1990); Campbell v. Hosp. Serv. Dist. No. 1, 768 So.20 803 (La. Ct. App. 2000); Cornfeldt v. Tongen, 295 N.W.2d 638 (Minn. 1980); Bever v. State Bd. of Registration for Healing Arts, 2001 WL 68307 (W.D. Mo. Jan. 30, 2001).

209 Frakes, 1997 Tenn. App. LEXIS 597, at*!.

$210 I d$. at $* 3$ (basing the argument on FED. R. EVID. 801 ).

21) Id. at $* 9$.

212 Id. at *13-14 (noting that TENN. R. EvID. 803(17) is identical to FED. RULES EvID. 803(18)).

213 See, e.g., McCay v. Mitchell, 463 S.W.2d 710, 715 (Tenn Ct. App. 1970).

214 TENN. EVID. RULE 618 provides:

To the extent called to the attention of an expert witness upon crossexamination or relied upon by the witness in direct examination, statements contained in published treatises, periodicals, or pamphlets on a subject of history, medicine, or other science or art, established as a reliable authority by the testimony or admission of the witness, by other expert testimony, or by judicial notice, may be used to impeach the expert witness's credibility but may not be received as substantive evidence. 
guidelines admissible beyond instances of impeachment, ${ }^{215}$ albeit as an adjunct to oral testimony rather than as an exhibit. 216

While Frakes itself is, therefore, of limited applicability, it is easier to approve of the sentiment underlying Judge Koch's concurrence when he argued that "[c]linical practice guidelines have emerged within the past few years as one of the medical profession's responses to the perceived shortcomings in medical practice.... Rather than being a mere sampling of professional opinion, these guidelines provide consensus standards of conduct that are both clearer and more rational than those currently used to identify professional negligence." 217 Indeed, in everyday litigation practice it is likely that clinical guidelines will sidle into medical malpractice trials in the manner approved by the majority opinion in Frakes, which noted, "this is not a situation where a jury is improperly exposed to unexamined hearsay . . . the result was exactly the same as if one of the experts had been asked to go to the board and list the standards to be applied in interpreting the stress test."218

Assuming admissibility, however, the issue arises as to the legal, normative effect of such evidence. Several discrete questions arise which reinforce the importance of the clinical practice issue and its potential for the resolution of legal as well as medical issues when integrated into expert systems. For example, can

215 FED. R. EvID. 803(18) provides:

Learned treatises. To the extent called to the attention of an expert witness upon cross-examination or relied upon by the expert witness in direct examination, statements contained in published treatises, periodicals, or pamphlets on a subject of history, medicine, or other science or art, established as a reliable authority by the testimony or admission of the witness or by other expert testimony or by judicial notice. ...

Cf. TENN. Evid. R. 803 (18) Advisory Commission Comment: "Learned trestises can be used to impeach an expert but are not themselves admissible to prove the truth of their contents. No good reason exists to permit hearsay to be taken as true just because it is written in books. Fed. R. Evid. 803 (18) is contra." See also Greathouse v. Rhodes, 618 N.W.2d 106, 115-16 (Mich. Ct. App. 2000) (applying minority impeachment rule).

216 "If admitted, the statements may be read into evidence but may not be received as exhibits." FED. R. EVID. 803(18). See also Tart v. McGann, 697 F.2d 75, 78 (2d Cir. 1982):

[Rule $803(18)$ ] explicitly permits the admission of medical literature as substantive evidence "to the extent called to the attention of an expert witness upon cross-examination or relied upon by him in direct examination" as long as it is established that such literature is authoritative.

…

Most commentators found the hearsay objections to learned treatise evidence unconvincing, and recommended that treatises be admitted as substantive evidence. Some commentators went so far as to suggest that treatises be admitted independently of an expert's testimony. . . . The Advisory Committee rejected this position, noting that a treatise might be 'misunderstood and misapplied without expert assistance and supervision.' Accordingly, the Rule permits the admission of learned treatises as substantive evidence, but only when an expert is on the stand and available to explain and assist in the application of the treatise ...." (citations omitted).

217 Frakes, 1997 Tenn. App. LEXIS 597 at, *15-16 (reference omitted).

218 Id. at *11. See also Davenport By and Through Davenport v. Ephraim McDowell Mem'l Hosp., Inc., 769 S.W.2d 56, 61-62 (Ky. App. 1988):

The next exhibit considered objectionable by the appellants was identified as "Guidelines for Standards of Care and Management Standards in the Post Anesthesia Care Unit," published by the American Society of Post Anesthesia Nurses. Appellants regard this document as a learned treatise, but we do not. It is more akin to the Public Safety Commission's standards considered by the court in Vaught's Adm'x v. Kentucky Utilities Co. The court found them to be helpful as a guide for measuring care. We regard the nurses' publication in a similar fashion, and see no error in its being admitted as an exhibit (citations omitted). 
compliance or noncompliance with practice guidelines, standing alone, sustain a verdict rendered in the absence of any countervailing evidence of customary standards?219 Could such evidence sustain a verdict in the face of countervailing expert testimony as to customary standards?220 Would a practice guideline, or the traditional evidence of customary practices with which it was competing, be given the status of "exercise of judgment" 221 or that of a "school of thought"222 or "respectable minority"?223 Should courts use practice guidelines symmetrically or asymmetrically (i.e., for inculpatory as well as exculpatory purposes)?224

Kacmar has argued, primarily in the context of journal data, that "[c]omputer information technology is progressing at an unprecedented rate, as is the volume of innovative medical literature. Nevertheless, it seems that mandating the use of, or even admitting evidence gleaned from, a computerized MEDLINE search is, as yet, unworkable, particularly in light of the database's inherent limitations." 225 Kacmar has noted reasons given for this negative conclusion, including the fact that the medical databases are incomplete, the metadata is unreliable, the data-mining tools are imperfect and high service and sorting costs are imposed. 226

These arguments will be considerably weaker in the face of the knowledge bases that will be built on top of the HIPAA-EDI inspired architecture. The costs of these systems will be borne by institutions and will reflect a far more robust data set; not only MEDLINE, but practice guidelines and best practices. Data-mining will be improved by using fuzzy logic ${ }^{227}$ systems. The most important refinement that the next generation of systems will bring is the development of systems that are automated and personalized.228 These will not be passive systems that require physicians to access them and compose searches (although that will and must remain

219 See, e.g., Frakes, 1997 Tenn. App. LEXIS 597, at*15-16. (“[T]hey should not necessarily be viewed as conclusive evidence of the standard of care. Proof of compliance with practice guidelines should not necessarily establish due care; just as proof of noncompliance should not establish negligence per se." (reference omitted)).

220 See, e.g., United Blood Servs. v. Quintana, 827 P.2d 509, 519 (Colo. 1992) (holding that blood bank from which woman received AIDS-contaminated blood should be judged using ordinary principles of negligence, and that the defendant's conduct should be measured against what a reasonable and prudent blood bank would or should have done under the same or similar circumstances); Helling v. Carey, 519 P.2d 981, 984 (Wash. 1974) (finding that ophthalmologist breached reasonable standard of care by failing to administer a glaucoma test to woman with substantial vision loss).

221 See, e.g., Velazquez v. Portadin, 751 A.2d 102, 107-11 (N.J. 2000) (finding that a physician's professional conduct implicates only the exercise of reasonable care in the performance of a medical procedure, and not the exercise of medical judgment in selecting among acceptable and medically reasonable courses of treatment).

222 See, e.g., Clark v. Doe, 695 N.E.2d 276, 302-03 (Ohio 1997) (finding a two schools of thought jury instruction misleading in case involving poorly treated broken leg); Levine $v$. Rosen, 616 A.2d 623, 626-27 (Pa. 1992) (finding no evidence of divergent opinions, the court rejected the two schools of thought defense in malpractice case involving negligent diagnosis of breast cancer).

223 See, e.g., State Bd. of Med. Examiners v. McCroskey, 880 P.2d 1188, 1194-95 (Colo. 1994) (rejecting the respected minority rule, noting that the accepted standard of medical practice can not be ascertained by "counting how many physicians follow a particular practice").

224 See Michelle M. Mello, Of Swords and Shields: The Role of Clinical Practice Guidelines in Medical Malpractice Litigation, 149 U. PA. L. REV. 645, 666 (2001).

225 Donald E. Kacmar, The Impact of Computerized Medical Literature Databases on Medical Malpractice Litigation: Time for Another Helling v. Carey Wake-Up Call?, 58 OHIO ST. L.J. 61 7, 654 (1997).

226 Id. at $639-53$

227 For a definition, see whatis?com, at http://whatis.techtarget.com/definition/0,289893, sid9_gci212172,00.html (last visited Nov. 11, 2001).

228 See, e.g., PERSONALIZATION CONSORTIUM, at http://www.personalization.org/ (last visited Nov. 17, 2001). 
an option), but will be triggered by the CPR and specific medical interventions.

Sorting costs will be dramatically reduced because the systems will seek data that is specific or personalized to the individual patient's CPR in question. Notwithstanding, and as Rosoff has persuasively argued, "[d]irect application of CPGs [Clinical Practice Guidelines] as setting the legal standard for medical care is an extreme recognition that seems inappropriate and unlikely at this relatively early stage of development of CPGs." 229 . Mello has gone further, arguing that:

[I]ncreased reliance on clinical practice guidelines to establish the standard of care in medical malpractice cases would be undesirable whether the guidelines are used in an inculpatory or an exculpatory fashion. Among the reasons for disallowing the inculpatory use of CPGs is that CPGs do not appear to represent custom in most instances. Compliance with most guidelines is presently quite low, so that the guidelines cannot be said to embody prevailing medical practice. Departing from custom as the anchor of the standard of care, and relying on the prescriptions of CPGs instead, could undermine the deterrent function of tort law by increasing the amount of uncertainty physicians face in determining what the law requires of them. 230

The doubts that so many have expressed about using practice guidelines as the standard of care in malpractice cases has led Rosoff to call for a federal certification program for practice guidelines to be operated by AHRQ.231 Absent such a system, and while justice, efficiency and other public policy concerns may militate against the broader legal utilization of practice guidelines, operationally, the battle against practice guidelines is almost over. Institutional informational systems will be fuelled by this type of "objective" data. Computer surveillance systems will operate on the basis that practice guidelines and their fellow travelers represent the correct methodology and the conclusive metric. Adverse result reporting will reflect that objectivity.

\section{B. RESPONDING to NEW BUSINESS MOdELS}

If bricks-and-mortar healthcare businesses are only now, with nudging from HIPAA-EDI, realizing the potential of their information architecture, they are somewhat more advanced in their technologically-mediated $\mathrm{B} 2 \mathrm{C}$ ventures. Marketing is the lifeblood of credence-good businesses, such as hospitals and pharmaceutical companies who have been cut off from patients by MCOs. Here, institutional progress is driven less directly by HIPAA-EDI related infrastructure and more by the related general acceptance of technology within institutions. It should be noted, however, that one of the strongest battles during the HIPAA privacy regulations comment period implicated the continued ability of healthcare entities to

229 Amold J. Rosoff, The Role of Clinical Practice Guidelines in Health Care Reform, 5 HEALTH MATRIX 369, 383-84 (1995).

230 Mello, supra note 224, at 708-09. Cf. Richard E. Leahy, Comment, Rational Health Policy and the Legal Standard of Care: A Call for Judicial Deference to Medical Practice Guidelines, 77 CALIF. L. REV. 1483, 1506 (1989) (arguing that courts should take judicial notice of practice guidelines promulgated by legitimate medical authorities as the legal standard of care).

231 Arnold J. Rosoff, Evidence-Based Medicine and the Law: The Courts Confront Clinical Practice Guidelines, 26 J. Health POL., POL'y \& LAW 327, 356 (2001). 
use $\mathrm{PHI}^{232}$ for their own marketing purposes. The final regulation permits providers to use PHI without prior authorization for marketing their own products and services and those of third parties.233 The regulation is subject only to an opt-out provision for the patient after the initial marketing contact.234 This provision has been the subject of considerable criticism by privacy advocates.235 Similarly, the regulation allows for providers to use a limited subset of PHI for fundraising purposes. ${ }^{236}$

As provider databases swell with information about their patients, and providers become more adept at exploiting new technologically-mediated marketing channels-including one-to-one marketing via the Internet-their marketing practices will evolve and themselves implicate liability laws. This is already the case with television, print and Internet advertising of prescription pharmaceuticals. The "old" learned intermediary rule, which set up the prescribing physician as the primary defendant in a failure to warn case, ${ }^{237}$ is being vaporized by the growth of direct-toconsumer (DTC) pharmaceutical advertising, ${ }^{238}$ which will necessitate a reassessment of manufacturers' liability. ${ }^{239}$

Similarly, as healthcare institutions increase their marketing presence on the Web and elsewhere, they are likeiy to stress their own brand and reputation more than that of the individual physicians they credential. Courts already are noticing this marketing trend. They seem prepared to adapt malpractice liability rules, which historically have looked at individual physicians as the default defendants in malpractice cases, and accelerate the movement toward institutional liability. 240

232 Individually identifiable health information is information that is a subset of health information, including demographic information collected from an individual, and:

(1) Is created or received by a health care provider, health plan, employer, or health care clearinghouse; and

(2) Relates to the past, present, or future physical or mental health or condition of an individual; the provision of health care to an individual; or the past, present, or future payment for the provision of health care to an individual; and

(i) That identifies the individual; or

(ii) With respect to which there is a reasonable basis to believe the information can be used to identify the individual.

Protected health information means individually identifiable health information:

(1) Except as provided in paragraph (2) of this definition, that is:

(i) Transmitted by electronic media;

(ii) Maintained in any medium described in the definition of electronic media at

$\$ 162.103$ of this subchapter; or

(iii) Transmitted or maintained in any other form or medium.

45 C.F.R. $\$ 164.501(2001)$ :

233 ld.

234 45 C.F.R. $\$ 164.514(\mathrm{e})(2001)$.

235 See Robert O'Harrow, Fatient Files Opened to Marketers, Fundraisers, WASH. POST, Jan. 16, 2001, at E01.

23645 C.F.R. $\$ 164.514(0)(2001)$.

237 See Tracy v. Merrell Dow Pharms., Inc., 569 N.E.2d 875, 880 (Ohio 1991) (holding that physician established necessary relationship with plaintiff to be considered a learned intermediary and had duty to warn patient of risks of investigational drug)

238 See generally Direct-to-Consumer Promotion, 61 Fed. Reg. 24,314 (May 14, 1996); Draft Guidance for Industry; Consumer-Directed Broadcast Advertisements; Availability, 62 Fed. Reg. 43,171 (Aug. 12, 1997); Guidance for Industry on Consumer-Directed Advertisements; Availability, 64 Fed. Reg. 43,197 (Aug. 9, 1999).

239 See, e.g., Perez v. Wyeth Labs. Inc., 734 A.2d 1245, 1263 (N.J. 1999). See also Vitanza v. Upjohn Co., 214 F.3d 73 (2d Cir. 2000).

240 See, e.g., Kashishian v. Port, 481 N.W.2d 277, 278 (Wis. 1992). See also Jones v. Chicago HMO Ltd. 730 N.E.2d 1119 (Ill. 2000); Petrovich v. Share Health Plan 719 N.E.2d 756 (IIl. 1999); 
Bricks-and-mortar healthcare businesses with innovative business models share healthcare marketing space with entirely new entities that will operate as information brokers or infomediaries between providers and patients. 241 Bates and Gawande have observed that, "The Internet changes the exercise of quality measurement in several ways. First, quality information-including reputation-will be more readily available. Second, consumers will increasingly use it. Third, the Internet provides a low-cost, standard platform that will make it vastly easier for providers to collect quality information and pass it on to others." 242 The liability correlate to this phenomenon is that the eHealth defendant pool will be swelled by an increasing number of intermediaries and infomediaries. As more data becomes available through modern IT systems, data-mining will become more sophisticated and outputs more personalized, so the factual realm of "foreseeable" risk will expand, as will the number of parties who have actual or constructive foresight of such risks. ${ }^{243}$

Even infomediaries with recognized error-reducing credentials will be swept into the expanding defendant base. For example, Rosoff has raised the issue of the potential liability of those who promulgate practice guidelines. ${ }^{244}$ In the purely online world of Web sites that provide medical information and advice, a similar question must be asked as to the liability of trustmarking and kitemarking organizations. Several highly respected organizations have put forward selfregulatory codes of conduct with accompanying trustmarks, seals or kitemarks for those who comply. ${ }^{245}$ Such systems are not without their difficulties 246 and critics. ${ }^{247}$ Trustmarking organizations that provide inaccurate "false positive" endorsements of online medical advice may well fall foul of Section 324A of the Restatement (Second) of Torts, ${ }^{248}$ which has been successfully utilized in the offline world against certifiers or endorsers of defective products. ${ }^{249}$ Despite this, with regulatory agencies

Gilbert v. Sycamore Mun. Hosp., 622 N.E.2d 788 (IIl. 1993); Sword v. NKC Hosps., Inc., 714 N.E.2d 142 (Ind. 1999). See discussion infra of institutional liability for failure to provide informed consent accompanying text at note 338 .

241 See supra text accompanying notes 177

242 David W. Bates \& Atul A. Gawande, The Impact of The Internet on Quality Measurement, HEALTH AFF., Nov./DEC., at 104, 104 (2000).

243 See generally Terry, supra note 188 , at $773-74$

244 Rosoff, supra note 229, at 238.

245 INTERNET HEALTHCARE COALITION, eHealth Code of Ethics, at http://www.ihealthcoalition.org/ ethics/ehcode.html (2000); HEALTH ON THE NET FOUNDATION, HonCode, at http:/www.hon.ch/HONcode/ Conduct.html (1997); HI-ETHICS, INC., Health Internet Ethics: Ethical Principles For Offering Internet Health Services to Consumers, at http:/www.hiethics.org/Principles/index.asp (last visited Nov. 12, 2001).

246 See Alcjandro R. Jadad \& Anna Gagliardi, Rating Health Information on the Internet: Navigating to Knowledge or to Babel?, 279 JAMA 611, 611 (1998).

247 Tony Delamothe, Editorial, Quality of Websites: kitemarking the west wind, 321 BRIT. MED. J. $843,843(2000)$.

248 One who undertakes, gratuitously or for consideration, to render services to another which he should recognize as necessary for the protection of a third person or his things, is subject to liability to the third person for physical harm resulting from his failure to exercise reasonable care to protect his undertaking, if

(a) his failure to exercise reasonable care increases the risk of such harm, or

(b) he has undertaken to perform a duty owed by the other to the third person, or

(c) the harm is suffered because of reliance of the other or the third person upon the undertaking.

RESTATEMENT (SECOND) OF TORTS $\$ 324$ A (1997)

249 For example, in Hempstead v. Gen. Fire Extinguisher Corp., 269 F. Supp. 109, 118 (D. Del. 1967), Underwriter's Laboratories, a well-known non-profit testing laboratory, was held potentially liable after a whitelisted fire extinguisher exploded. The court noted: "The alleged failure of Underwriters to exercise reasonable care in approving the design of the extinguisher has obviously increased the risk of harm to plaintiff over that which would have existed if reasonable care had been 
practically unable to extend their immediate work beyond the most obvious types of fraudulent marketing, ${ }^{250}$ such infomediaries are likely to proliferate and even receive governmental encouragement.

\section{ONLINE HEALTH INFORMATION}

As online healthcare expands its reach, volume and sophistication, the courts may well turn their attention to the liability of online advice sites. As I have argued elsewhere, malpractice-like actions against medical advice Web sites that primarily supply information are fraught with technical legal difficulties, including freedom of speech arguments, ${ }^{251}$ potential statutory immunities ${ }^{252}$ and a sparse history of publishers being held responsible for "advice" or "how-to" books. ${ }^{253}$ Even where the perpetrators are traditional healthcare entities such as doctors, and thus apparently amenable to less revolutionary liability theories, consumers injured by their acts or omissions may find their traditional theories of liability practically stymied by a discovery that the defendant's malpractice insurance does not cover such online activities. ${ }^{254}$

Taken as whole, therefore, the HIPAA-EDI architecture will compel or stimulate infrastructure upon which providers will build sophisticated information systems or, less directly, furnish both patients and providers with incentives to enter the online medical space. The legal standard of care inevitably will react, adopting increasingly objective standards that reflect the quality-driven data that will flow through our healthcare delivery system and the expert systems which will fine tune that data to solve individual patients' health needs. Furthermore, as the data proliferates, it seems unavoidable that courts will extend the reach of malpractice-like doctrine to new activities and new actors. Just as technology has the potential to rehabilitate our delivery system by reducing error, our courts will not likely ignore the reach or the normative effects of its implementation.

\section{CONSENT TO DISCLOSURE IN PRIVACY REGIMES AND INFORMED CONSENT}

While privacy will have medium and long-term effects on the quality of care, its most immediate effects may well be on a subset of malpractice law: informed

exercised." Id. This proposition was later approved by the court in Arnstein v. Mfg. Chemists Ass ', 414 F. Supp. 12, 14-15 (E.D. Pa. 1976), which also posited potential liability based on the closely related Restatement (Second) of Torts section 323. See also Nicolas P. Terry, Rating the "Raters": Legal Exposure of Trustmark Authorities in the Context of Consumer Health Informatics, 2 J. MED. INTERNET RESEARCH e18 (2000), available at http://www.jmir.org/2000/3/e18.

250 See, e.g., Press Release, FED. TRADE COMM'N, "Operation Cure.All" Wages New Battle in Ongoing War Against Internet Health Fraud, June 14, 2001, (describing the joint FTC and FDA initiative targeting the fraudulent marketing and sale of dietary supplements and other products on the Internet), available at http://www.ftc.gov/opa/2001/06/cureall.htm. See also Greg Winter, U.S. Vows More Scrutiny of Health Ads on Net, N.Y. TIMES, June 15, 2001, at C4; David McGuire, Govt. Agencies Crack Down On Online Comfrey Sales, NEwSBYTES, (July 9, 200I), at http://www.newsbytes.com/news/01/167742.html..

251 Nicolas P. Terry, Cyber-Malpractice: Legal Exposure for Cybermedicine, 25 AM. J.L. \& MED. 349,352 (1999).

252 E.g., 47 U.S.C. $\$ 230$ (1994) (providing arguable ISP/Web publisher immunity). See Jane Doe One v. Oliver, 755 A.2d 1000, 1002 (Conn. Super. Ct. 2000).

253 Terry, supra note 251, at 354-55

254 Linda O. Prager, Doctors May Face Liability Risks in Bidding for Patients on Web Auction Sites, AM. MED. NEwS, Sept. 4, 2000, available at http://www.ama-assn.org/sci-pubs/amnews/pick_00/ prsa0904.htm 
consent. This section examines the PIHI disclosure rules and how they intersect with the substance of modern consent law and the operational aspects of consent. Specifically, the very strongly delineated consent-to-disclosure provisions in the PIHI regulations are likely to influence the way institutions deal with informed consentrelated disclosure, resulting in an operational co-joining of their processes. This section also examines whether the PIHI regulations and the increased scrutiny they should bring to patient consent-to-disclose will increase the prevalence and robustness of informed consent. Conversely, it must be asked whether informed consent will suffer at the hands of an increasingly mechanistic approach to such events. This section concludes with a discussion of how the HIPAA-EDI inspired architecture will facilitate new technologically-mediated healthcare products and services and will require an expansion of informed consent to cover such physicianpatient interactions.

\section{A. THE PIHI SYSTEM OF CONSENT AND AUTHORIZATION}

As noted above, HIPAA-mandated privacy creates no serious disincentives to the collection of health information. Rather, the regulatory model is one of controlled and gradated disclosure. PIHI regulates disclosure and use in two ways. First, it applies a global "minimum necessary" rule to disclosures and uses;255 although it derogates from that rule in cases of treatment or when the disclosure is required by law. 256 Second, PIHI invokes gradated levels of permissions dependent on the type of information utilization contemplated. These levels are: (1) required disclosure to the patient or to the DHHS Office for Civil Rights257 (OCR);258 (2) permitted disclosure to a broad range of public health, law enforcement and judicial authorities, as required by law and subject to various conditions;259 (3) consented-to disclosure for treatment, payment or healthcare operations (TPO) purposes;260 and (4) authorized disclosures for other purposes. ${ }^{261}$ Types (3) and (4) are most likely to share conceptual and operational space with treatment-related informed consent.

PIHI primarily distinguishes between consent and authorization to give effect to the distinction made in the rules between treatment-related and other disclosures or uses. Consent to disclosure of PHI is required "prior to using or disclosing protected health information to carry out treatment, payment, or health care operations." 262 In other situations, authorization is required.263 These two types of acquiescence to disclosure differ primarily in their detailed operational aspects. Consent is considerably more pro forma; it may be general, ${ }^{264}$ brief, ${ }^{265}$ given one time ${ }^{266}$ and a

25545 C.F.R. $\$ 164.502$ (b)(1) (2001) ("When using or disclosing protected health information or when requesting protected health information from another covered entity, a covered entity must make reasonable efforts to limit protected health information to the minimum necessary to accomplish the intended purpose of the use, disclosure, or request.").

25645 C.F.R. $\S 164.502(b)(2)(2001)$.

25745 C.F.R. $\S 164.502(a)(2)(2001)$.

258 OCR has been given enforcement jurisdiction. See Statement of Delegation of Authority to the Office for Civil Rights, 65 Fed. Reg. 82,831 (Dec. 28, 2000).

25945 C.F.R. $\$ 164.512(2001)$.

26045 C.F.R. $\$ 164.506(2001)$.

26145 C.F.R. $\$ 164.508(2001)$.

262 45 C.F.R. \$164.506(a) (2001).

263 See 4S C.F.R. $§ 164.508$ (2001).

264 "The consent document may be brief and may be written in general terms." GUIDANCE/Q\&AS, supra note 37.

265 A consent document is brief (may be less than one page). It must refer to the 
provider may refuse to treat a patient who refuses consent. ${ }^{267}$ An individual may request restrictions on uses or disclosures of health information for TPO, but the provider need not agree to the restriction requested. 268 Treatment generally cannot be conditioned on authorization (for example, to the hospital selling PHI to a pharmaceutical company) ${ }^{269}$ and in most cases cannot be general or compound, but rather, must be specific to the disclosure permission requested.270 Both consents and authorizations may be revoked. 271

The consent-to-disclosure instrument must be in plain language and explain or refer to other PIHI rights that the patient has. ${ }^{272}$ It may be combined with and sought at the same time (e.g., upon admission) as other permissions such as informed consent. ${ }^{273}$ An authorization instrument also must be in plain language ${ }^{274}$ but generally may not be part of a compound document. ${ }^{275}$ It is required to be more detailed than a consent instrument with considerably more specificity as to the PHI to be disclosed, the purposes of the disclosure and the patient's legal rights. ${ }^{276}$ In a narrow range of situations, authorization can be achieved through a patient opt-out provision, such as in the marketing rules discussed above, ${ }^{277}$ or through facility directories. ${ }^{278}$

\section{B. POST-MODERN INFORMED CONSENT}

Similar to the PIHI rules' distinction between consent and authorization, postmodern informed consent ${ }^{279}$ law is not a singular concept. ${ }^{280}$ The original, pre-

Id.

notice and must inform the individual that he has the opportunity to review the notice prior to signing the consent. The Privacy Rule does not require that the individual read the notice or that the covered entity explain each item in the notice before the individual provides consent. We expect that some patients will simply sign the consent while others will read the notice carefully and discuss some of the practices with the covered entity.

266 A patient's written consent need only be obtained by a provider one time .... A health care provider needs to obtain consent from a patient for use or disclosure of PHI only one time. This is true regardless of whether there is a connected course of treatment or treatment for unrelated conditions. A provider will need to obtain a new consent from a patient only if the patient has revoked the consent between treatments.

Id.

26745 C.F.R. $\$ 164.506($ b) $(2001)$

268 45 C.F.R. \$ $164.506(\mathrm{c})(4)(2001)$.

26945 C.F.R. $\$ 164.508(\mathrm{~b})(4)(2001)$.

27045 C.F.R. $\$ 164.508(b)(3)(2001)$.

27145 C.F.R. $\$ \S 164.506(\mathrm{~b})(5), 164.508(\mathrm{~b})(5)(2001)$

27245 C.F.R. $\$ 164.506$ (c) (2001).

27345 C.F.R. \$164.506(b)(4) (2001).

274 See, e.g., 45 C.F.R. \$ 164.508(c)(2) (2001).

275 45 C.F.R. \$164.508(b)(3) (2001).

276 45 C.F.R. $\$ 164.508$ (c)(d)(e)(f) (2001).

277 See supra text accompanying note 234.

27845 C.F.R. $\$ 164.510$ (2001).

279 See generally Nicolas P. Terry, Apologetic Tort Think: Autonomy and Information Torts, 38 ST. LouIS L.J. 189, 189-90 (1993) (contending that that the doctrine of informed consent does not, as commonly assumed, have a fully developed ethical structure).

280 See generally Frances H. Miller, Health Care Information Technology and Informed Consent: Computers and the Doctor-Patient, Relationship, 31 IND. L. REV. 1019,1032 (1998) (discussing how "the theoretical basis for a physician's negligent failure to secure an informed patient consent to therapy has come a very long way from the original battery rationale for requiring patient 
patient autonomy notion of medical consent functioned as a defense to the tort of battery, where the touching was done by a healthcare professional. ${ }^{281}$ Informed consent had its genesis in cases that were tried under a battery theory, in which there had been actual consent, but the plaintiff argued that the consent had been vitiated by nonexistent or inaccurate information. ${ }^{282}$. The modern approach was initiated when the courts decided that vitiation cases, which featured intentional contact but unintended harm, did not belong in the intentional torts category because of either doctrinal or allocational rationales. ${ }^{283}$ Thereafter, the courts have distinguished between cases involving an absence of consent, which are properly brought in battery, ${ }^{284}$ and those that involved consent actually given but allegedly given without adequate disclosure of risk, which are properly brought in malpractice. ${ }^{28 .}$

consent to medical touching").

281 Terry, supra note 279 , at 192

282 See, e.g., RESTATEMENT (SECOND) OF TORTS \& 892B (1997). See, e.g., Micari v. Mann, 481 N.Y.S.2d 967 (N.Y.: Sup. Ct. 1984). Although no physical force was employed, the court found a teacher's requirement of sexual acts during class a form of sexual abuse which warranted punitive damages. $I d$. at 970 .

283 See, e.g., Trogun v. Fruchtman, 207 N.W.2d 297, 311 -13 (Wis. 1973):

First, the act complained of in these cases simply does not fit comfortably within the traditional concepts of battery-the intent to unlawfully touch the person of another. In cases such as the instant one, physicians are invariably acting in good faith and for the benefit of the patient. While the result may not be that desired, the act complained of is surely not of an antisocial nature usually associated with the tort of assault and battery or battery. ... Second, and related to the first, the failure to inform a patient is probably not, in the usual case, an intentional act and hence not within the traditional concept of intentional torts. Third, the act complained of in informed consent cases is not within the traditional idea of "contact" or "touching." In the typical situation, as here, the physician impeccably performs the surgery or other treatment. Complained of are the personal reactions to such treatment which are unanticipated by the patient. ... Fourth, a valid question exists with respect to whether a physician's malpractice insurance covers liability for an arguably "criminal" actbattery. . . . Fifth, these essentially negligence cases do not fit the traditional mold of situations wherein punitive damages can be awarded. For these reasons, we conclude it is preferable to affirmatively recognize a legal duty, bottomed upon a negligence theory of liability, in cases wherein it is alleged the patient-plaintiff was not informed adequately of the ramifications of a course of treatment.

See also Matthies v. Mastromonaco, 733 A.2d 456, 461 (N.J. 1999) ("The rationale for basing an informed consent action on negligence rather than battery principles is that the physician's failure is better viewed as a breach of a professional responsibility than as a nonconsensual touching").

284 See, e.g., McNeil v. Brewer, 710 N.E.2d 1285, $1288-89$ (1ll. App. Ct. 1999):

To state a claim for battery based upon a lack of informed consent to medical procedures, a plaintiff must allege a total lack of consent to a medical procedure involving an intentional unauthorized touching of the plaintiff's person by another. The elements of such a claim consist of (1) an intentional act on the part of the defendant; (2) a resulting offensive contact with the plaintiff's person; and (3) a lack of consent to the defendant's conduct. An "offensive contact" may be established by proof that the defendant intended to cause the plaintiff, directly or indirectly, to come into contact with a foreign substance in a manner which the plaintiff would reasonably regard as offensive (references omitted).

See also Brzoska v. Olson, 668 A.2d 1355, 1363-64 (Del. 1995) (holding that "the incidental touching of a patient by an HIV-infected dentist while performing ordinary, consented-to dental procedures is insufficient to sustain a battery claim in the absence of a channel for HIV infection."); Gaskin v. Goldwasser, 520 N.E.2d 1085, 1095 (111. App. Ct. 1988) (finding that removal of patient's lower teeth was without consent and thus sufficient to support a battery theory of recovery).

285 See, e.g., Cobbs v. Grant, 502 P.2d 1, 8 (Cal. 1972). See also Lugenbuhl v. Dowling, 701 So. 2d 447,456 (La. 1997) (holding that doctor failed to obtain adequate informed consent when he failed to discuss with a patient the risks of mesh use in hemia repair); Perna v. Pirozzi, 457 A.2d 431, 440-41 (N.J. 1983) (holding that a patient who consents to surgery by one surgeon, but is actually operated on by another, has an action for malpractice against the former and for battery against the latter). 
Originally, "failure to disclose" cases were governed by traditional malpractice principles, particularly the use of a customary practice standard derived from expert testimony. ${ }^{286}$ As this negligence-based line of cases came under the influence of patient rights and personal autonomy arguments, ${ }^{287}$ however, some jurisdictions began to assess the appropriate level of disclosure against a patient standard; based on expectations or a need to know that, arguably, better reflects the physician-patient informational asymmetry. 288

Similar to the question of the standard of disclosure, courts have struggled to define the reach of the duty. For example, many courts limit the duty to disclose to surgical risks. ${ }^{289}$ Some courts still view informed consent cases as legally-deficient, "bad results" cases in which the plaintiff is seeking to promote a theory of liability other than conventional malpractice (e.g., negligent diagnosis or treatment) in a situation that has overall merit yet is flawed (i.e., on evidentiary grounds). ${ }^{290}$ For a majority of courts, therefore, the informed consent doctrine supports a relatively unsophisticated, even literal consent model derived from basic autonomy principles.

In contrast, the fundamental informational asymmetry between patient and physician, and the goal of having the patient more involved in the decision making process, have had a relatively minor effect on doctrinal development. 291 As a result, informed consent law is still primarily about consent, not the information that is

286 See, e.g., Campbell v. Palmer, 568 A.2d 1064, 1067 (Conn. App. 1990)

287 See generally JAY KATZ, THE SILENT WORLD OF DOCTOR AND PATIENT (1984) (discussing the obstacles between meaningful physician patient interaction); see also Jay Katz, Informed ConsentA Fairy Tale? Law's Vision, 39 U. PITT. L. Rev. 137 (1977).

288 The classic case remains that of Canterbury v. Spence, 464 F.2d 772 (D.C.Cir. 1972). See also Pluger v. Physicians Ins. Co., 549 N.W.2d 286 (Wis. Ct. App. 1996); Largey v. Rothman, 540 A.2d 504 (N.J. 1988). See generally the appendix in Ketchup v. Howard, 543 S.E.2d 371 (Ga. Ct. App. 2000 ), providing a summary of the law on the issue of informed consent. Some legislatures have also entered the fray:

"Informed consent" means the consent of a patient to the performance of health care services by a health care provider given after the health care provider has informed the patient, to an extent reasonably comprehensible to general lay understanding, of the nature of the proposed procedure or treatment and of the risks and alternatives to treatment or diagnosis which a reasonable patient would consider material to the decision whether or not to undergo the treatment or diagnosis.

Del. Code AnN. tit. 18, $\S 6801(6)$ (2000). Cf. Tenn. Code AnN. $\$ 29-26-118(2000)$ :

In a malpractice action, the plaintiff shall prove by evidence. . . that the defendant did not supply appropriate information to the patient in obtaining informed consent (to the procedure out of which plaintiff's claim allegedly arose) in accordance with the recognized standard of acceptable professional practice in the profession and in the specialty, if any, that the defendant practices in the community in which the defendant practices and in similar communities.

289 Morgan v. MacPhail, 704 A.2d 617,618 (Pa. 1997) (holding that informed consent was not required in cases involving non-surgical procedures).

290 The relationship is not accidental. Plaintiffs are less likely to complain about deficient informed consent procedures if the treatment is completed satisfactorily. Equally, plaintiff's attorneys are unlikely to finance informed consent cases on a contingency fee basis in the absence of severe damage.

291 Cf. Carson v. Fine, 867 P.2d 610, 617 (Wash. 1994):

Mutual trust and confidence are essential to the physician-patient relationship, and from these elements flow the physician's obligations to fully inform the patient of his or her condition, to continue to provide medical care once the patient-physician relationship has been established, to refer the patient to a specialist if necessary, and to obtain the patient's informed consent to the medical treatment proposed. 
required to increase patient choice and participation. ${ }^{292}$ It is a doctrine that has not progressed beyond what Veatch describes as a transition status. ${ }^{293}$

Notwithstanding, a few courts have examined a broader approach to informed consent; such as expanding the doctrine's reach to include all treatment risks ${ }^{294}$ and other information such as non-medical risks, ${ }^{295}$ risks of non-treatment, ${ }^{296}$ hard data such as mortality statistics, 297 and specific physician impairments 298 or financial interests. 299 The "choice" model is illustrated by the Wisconsin statute that requires: "Any physician who treats a patient shall inform the patient about the availability of all alternate, viable medical modes of treatment and about the benefits and risks of these treatments." 300 As Miller has persuasively argued:

Doctors who ignore their patients' increasingly sophisticated knowledge base will probably find themselves in a shrinking minority, more vulnerable to informed consent litigation based on a failure to discuss therapy at more advanced levels of materiality. Even in those jurisdictions with physician-centered rather than patient-oriented standards of disclosure, patients will be likely to possess or know how to secure far greater medical knowledge than has been customary in the past and standards of disclosure will have to rise to accommodate that fact. A little knowledge can sometimes be a dangerous thing, but ignorance about the meaning

292 The classic exposition of this issue in the legal literature is Marjorie Maguire Shultz, From Informed Consent to Patient Choice: A New Protected Interest, 95 YALE L.J. 219 (1985).

293 "Consent may be what can be called a transition concept, one that appears on the scene as an apparently progressive innovation, but after a period of experience turns out to be only useful as a transition to a more thoroughly revisionary conceptual framework." Robert M. Veatch, Abandoning Informed Consent, HASTINGS CTR. REP., Mar./Apr. 1995, at 5. Veatch's work is further discussed infra text at note 305 .

294 See, e.g., Matthies v. Mastromonaco, 733 A.2d 456, 464 (1999):

It is not dispositive that the alternative that the physician recommends is more or less invasive than other alternatives. . . The critical consideration is not the invasiveness of the procedure, but the patient's need for information to make a reasonable decision about the appropriate course of medical treatment, whether invasive or noninvasive.

295 See, e.g., Arato v. Avedon, 858 P.2d 598, 599-600 (Cal. 1993) (declining to require mandatory disclosure of life expectancy in case where doctor allegedly failed to discuss the low life expectancy of a patient suffering from pancreatic cancer).

296 See, e.g., Truman v. Thomas, 611 P.2d 902, 907 (Cal. 1980) (holding that doctor had a duty to provide the decedent with all information material to her decision whether or not to undergo pap smear diagnostic test). $C f$. Vandi v. Permanente Med. Group, Inc., 9 Cal. Rptr. 2d 463, 467 (Cal. 1992) (holding that the duty of disclosure is predicated upon a recommended treatment or diagnostic procedure and the failure to recommend a procedure must be addressed under ordinary medical negligence standards).

297 See, e.g., Johnson v. Kakemoor 545 N.W.2d 495, 498 (Wis. 1996). Cf. Arato v. Avedon, 858 P.2d 598, 599-600 (Cal. 1993).

298 See, e.g., Johnson v. Kokemoor 545 N.W.2d 495, 498 (Wis. 1996). Cf. Duttry v. Patterson, 771 A.2d 1255, 1259 (Pa. 2001):

[I]nformation personal to the physician, whether solicited by the patient or not, is irrelevant to the doctrine of informed consent. Our holding should not, however, be read to stand for the proposition that a physician who misleads a patient is immune from suit. Rather, we are merely stating that the doctrine of informed consent is not the legal panacea for all damages arising out of any type of malfeasance by a physician.

299 See, e.g., Moore v. Regents of Univ. Cal., 793 P.2d 479, 482 (Cal. 1990) (holding that physician must disclose his proprietary and financial interests in stem cells extracted from a patient).

300 WIS. STAT. ANN. \$448.30 (West 2001). 
of knowledge can be worse. Both doctors and patients will be best served by working in tandem to harness the profusion of medical information unleashed by modern technology, in the interest of patient autonomy. The law of informed consent will require no less. 301

If courts have had much to say about the substantive standards and reach of informed consent, they have had remarkably little input into the mechanics of consent. Here, legislatures have been more active. For example, an Ohio statute states:

Written consent to a surgical or medical procedure or course of procedures shall, to the extent that it fulfills all the requirements in divisions (A), (B), and (C) of this section, be presumed to be valid and effective....

(A) The consent sets forth in general terms the nature and purpose of the procedure or procedures, and what the procedures are expected to accomplish, together with the reasonably known risks, and, except in emergency situations, sets forth the names of the physicians who shall perform the intended surgical procedures.

(B) The person making the consent acknowledges that such disclosure of information has been made and that all questions asked about the procedure or procedures have been answered in a satisfactory manner.

(C) The consent is signed by the patient . . .302

Such provisions are essentially limited to the mechanics of consent, seeking to shore up the legal effect of a written consent form. Notwithstanding, a signed consent form has more to do with "consent" type cases than failure to disclose allegations. Provisions such as the Ohio legislation are more likely to have an impact on "general" consents (e.g., to transfusions) acquired at the time of patient admission, rather than the specific issues and physician duties that call for disclosure prior to a specific course of treatment or surgery.

\section{EThical PeRspectives on PRIVACy AND CONSENT}

If the legal system's version of "consent" remains grounded in a somewhat literal, even mechanical, model, medical practitioners and ethicists are making more challenging suggestions. ${ }^{303}$ Indeed, one telling observation is that the current legal model has counter-productive tendencies:

Fully involving patients in clinical decisions is a challenging task for clinicians, and little training exists on the practice of effective informed decision making. What guidance exists is often based on legalistic notions of consent. For instance, the well-known mnemonic

301 Miller, supra note 280 , at 1042.

302 OHIo ReV. CODE ANN. $\S 2317.54$ (West 2001). See also FLA. STAT. ANN. $\$ 766.103(4)$ (a) (West 2001) ("A consent which is evidenced in writing . . . if validly signed by the patient or another authorized person, raise a rebuttable presumption of a valid consent").

303 For a summary of consent within different physician-patient models, see Marwan A. Habiba, Examining Consent within the Doctor-Patient Relationship, 26 J. MED. ETHICS 183 (2000). 
$P A R$ reminds the clinician to disclose the nature of the procedure, alternatives, and risks in any informed consent discussion. The rationale of this approach either satisfies an administrative requirement or protects oneself from liability, rather than viewing the decision making process as a meaningful path toward fostering patient involvement. 304

For Veatch, the retooling of informed consent is linked to the deconstruction of individual professional autonomy. ${ }^{305}$ This latter concept is clearly no stranger to a health law system that has embraced industrialized medicine. ${ }^{306}$ If Veatch views choice as the eventual replacement for consent, ${ }^{307}$ he identifies the primary obstacle as asymmetrical value systems of the clinician and her patient. ${ }^{308}$ The deep value pairing ${ }^{309}$ that he envisions, yet somewhat despairs of because of practical considerations, could well be promoted by the sophisticated health information systems that we are building. Modern ecommerce's one-to-one marketing thrives on the ability to personalize information using data explicitly provided for that purpose by the consumer. For example, a consumer may fill out a "mywebsite" questionnaire to personalize her Web experience ${ }^{310}$ and, more stealthily, the marketers may factor in a consumer profile harvested from the consumer's online behavior. In a related context I have argued that:

The ability to heavily personalize computer-mediated relationships may rehabilitate patient-physician relationships eroded by years of managed care, while the Web's ability to deliver rich information directly to consumers could reverse centuries of damaging informational asymmetry between patient and physician. 311

304 Clarence H. Braddock et al., Informed Decision Making in Outpatient Practice: Time to Get Back to Basics, 282 JAMA 2313,2313-14 (1999).

305 It is increasingly clear if one studies the theory of clinical decision making that there is no longer any basis for presuming that the clinician can even guess at what is in the overall best interest of the patient. If that is true, then a model in which the clinician guesses at what he or she believes is best for the patient, pausing only to elicit the patient's concurrence will no longer be sufficient. Increasingly we will have to go beyond patient consent to a model in which plausible options are presented (perhaps with the professional's recommendation regarding a personal preference among them, based on the professional's personally held beliefs and values), but with no rational or "professional" basis for even guessing at which one might truly be in the patient's best interest.

Veatch, supra note 293 , at 5 .

306 See, e.g., discussion accompanying supra note 240.

307 Veatch, supra note 293 , at 10.

308 Id.

309 As Veatch notes:

If, however, there were alignments, "value pairings," based on the most fundamental worldviews of the lay person and professional, then there would be some hope. This probably would mean picking providers on the basis of their religious and political affiliations, philosophical and social inclinations, and other deeply penetrating worldviews. To the extent that the provider and patient were of the same mind set, then there is some reason that the technically competent clinician could guess fairly well what would serve the patient's interest.

Id. at 11 .

310 For background, see Ted Kemp, Personalization Isn't a Product, at http://www. internetweek.com/newslead01/lead060101.htm (May 31, 2001).

311 Nicolas Terry, Access vs. Quality Assurance: The e-Health Conundrum, 285 JAMA 807 (2001). 
Facilitating such value symmetry through technology could move us closer to Veatch's concept of meaningful choice. It could also facilitate increased trust, particularly merit trust rather than status trust, ${ }^{312}$ and compassion. As Howe has observed, " $[\mathrm{B}] \mathrm{y}$ attending more to their own and to patients' feelings, careproviders can greatly assist patients who are emotionally vulnerable, and, by doing this, careproviders may also benefit all patients, by exploring with them the most private areas of their lives." 313

While the legal and ethical views of informed consent are not always in harmony, they are at least robust. In contrast, ethical constructs for medical privacy are still quite rudimentary. While the legal system routinely applies its breach of confidence rules to both physicians and institutional providers, 314 it is still something of an individual ethic, ${ }^{315}$ although it is slowly migrating to managed care entities. ${ }^{316}$ In an increasingly technology-mediated healthcare environment, privacy and confidentiality are viewed as "good things" and the occasions of lapses in patient protection are castigated when reported. ${ }^{317}$. Notwithstanding, there have been cautious attempts to capture some core values with respect to privacy and confidentiality. 318 For example, in dealing with online care, the eHealth Code of Ethics states:

People who use the Internet for health-related reasons have the right to expect that personal data they provide will be kept confidential. Personal health data in particular may be very sensitive, and the consequences of inappropriate disclosure can be grave. To protect users, sites that collect personal data should

- take reasonable steps to prevent unauthorised access to or use of personal data ...

- make it easy for users to review personal data they have given and to update it or correct it when appropriate

- adopt reasonable mechanisms to trace how personal data is used ...

- tell how the site stores users' personal data and for how long it stores that data

- assure that when personal data is "de-identified" (that is, when the user's name, email address, or other data that might identify him

312 See generally Allen Buchanan, Trust in Managed Care Organizations, 10 KENNEDY INST. ETHICS J. 189 (2000) (discussing the nature of trust in the physician-patient relationship).

313 Edward G. Howe, Leaving Laputa: What Doctors Aren 't Taught about Informed Consent, 11 J. CLINICAL ETHICS 3, 11 (2000).

314 See generally supra text accompanying note 58 .

315 See AM. MED. ASS'N, PRINCIPLES OF MEDICAL ETHICS, IV, at http://www.amaassn.org/ama/pub/category/2512.html (last visited Nov. 23, 2001) ("A physician shall respect the rights of patients, colleagues, and other health professionals, and shall safeguard patient confidences and privacy within the constraints of the law.").

316 See, for example, URAC's health web site accreditation program, at http://www.urac.org/ websiteaccreditation.htm (last visited Nov. 23, 2001). URAC's Health Web Site Standards, Version 1.0, are available at http://www.urac.org/programs/technologyhws.htm (last visited Nov. 23, 2001).

317 See, e.g., Janet Wells, Wrong MDs Got Patient Records; Psychiatric Privacy Violated, S.F. CHRON., Dec. 30, 2000 at A13; O'Harrow, supra nọte 235. See generally CAL. HEALTHCARE Found., REPORT ON THE PRIVACY POLICIES AND PRACTICES OF HEALTH WEB Sites, at http://ehealth.chcf.org/index.cfm?section=Privacy (last visited Nov. 23, 2001).

318 See generally Gostin, supra note 68, at 513-16. 
or her has been removed from the file) it cannot be linked back to the user. ${ }^{319}$

\section{INTERSECTION OF INFORMED CONSENT AND CONSENT TO DISCLOSE}

Although an abundance of case law details the duty of confidentiality a physician owes to her patient, ${ }^{320}$ the doctrine of informed consent has occupied most of the conceptual space concerning data flow between physician and patient. Despite the doctrine's limitations detailed herein, the overall trend has been to increase the flow of rich data between patient and physician.

One of the few reported cases to discuss the intersection between the duty of confidentiality and informed consent is Estate of Behringer v. Medical Center at Princeton. ${ }^{321}$ Plaintiff, who was also a member of the medical staff of the defendant hospital, was diagnosed with AIDS, a fact that swiftly became common knowledge within the hospital. The hospital's policy required that the patient be counseled prior to the administration of an HIV test, specifying that the blanket consent form used upon admission should not be used for this purpose. The patient had signed an informed consent that provided, "I . . . hereby give my consent . . . to have my blood tested for antibodies to HTLV III Virus as ordered by my physician. The results of the test will be reported only to the ordering physician." 322 This provision was inaccurate on its face because of the hospital's charting policies, which allowed for placement of laboratory test results on the patient's chart while not imposing any limitations on the availability and access of the chart within the institution. The court concluded:

[T]he failure of the Medical Center and [the] Director of the Department of Laboratories, who were together responsible for developing the misstated Informed Consent form, the counseling procedure and implementation of the charting protocol, to take reasonable steps to maintain the confidentiality of plaintiff's medical records, while plaintiff was a patient, was a breach of the Medical Center's duty and obligation to keep such records confidential. ${ }^{323}$

The message of cases like Behringer is that healthcare institutions and care providers must adopt a more holistic view of their responsibilities to the data and communications related to the patient. Predetermined, mechanistic occasions of "consent" are inadequate. Rather, dialog, choice, consequences of disclosure and consent must be ongoing and continually updated to reflect new data flowing into the record.

If the common law of consent and confidentiality are showing signs of edging closer together under a general umbrella of informational autonomy, it will be some

319 INTERNET HEALTHCARE COALITION, eHealth Code of Ethics (2000), at http://www.ihealthcoalition.org/ethics/ehcode.html; HEALTH ON THE NET FOUNDATION, HonCode, at http://www.hon.ch/HONcode/Conduct.html (1997); HI-ETHICS, INC., Health Internet Ethics: Ethical Principles For Offering Internet Health Services to Consumers, at http://www.hiethics.org/ Principles/index.asp (last visited Nov. 12, 2001).

320 See cases discussed at supra note 58.

321592 A.2d 1251 (N.J. Super. Ct. 1991).

322 Id. at 1271

323 Id. at 1273-74. 
time before it becomes clear whether the PIHI rules will hinder or heed that interaction. The basic philosophy behind PIHI as stated in the preamble to the rule is "to provide an opportunity for and to encourage more informed discussions between patients and providers about how protected health information will be used and disclosed within the health care system." 324 Operationally, DHHS believes that PIHI consent and authorization will have a non-contentious relationship with traditional consent law:

The Privacy Rule establishes a federal requirement that most doctors, hospitals, or other health care providers obtain a patient's written consent before using or disclosing the patient's personal health information to carry out treatment, payment, or health care operations (TPO). Today, many health care providers, for professional or ethical reasons, routinely obtain a patient's consent for disclosure of information to insurance companies or for other purposes. The Privacy Rule builds on these practices by establishing a uniform standard for certain health care providers to obtain their patients' consent for uses and disclosures of health information about the patient to carry out TPO. 325

Indeed, there are several potential positive intersections between PIHI and informed consent law and practice. First, HIPAA-EDI is likely to fuel an overall review of consents and authorizations within healthcare institutions. This process will in part be designed to examine the extent to which other documents can be efficiently combined in PIHI-mandated documents. The process also will be tasked with ensuring that PIHI consents and authorizations are not combined with documents that contain provisions inconsistent with the PIHI rules. ${ }^{326}$ It is highly likely that this review will lead to the redesign and possible standardization of related forms. For example, both consent and authorization instruments must be in "plain language." 327 Furthermore, PIHI authorization, and to a somewhat lesser extent, consent rules, are specific as to the inclusion of certain patient rights. For example, PIHI mandates that the form state the patient's right to revoke the consent ${ }^{328}$ or authorization. ${ }^{329}$ A right of revocation exists in common law informed consent; however, it is an issue that has seldom been discussed in that context. ${ }^{330}$ If

324 Standards for Privacy of Individually Identifiable Health Information, Final Rule, 65 Fed.

Reg. 82,462, 82,474 (Dec. 28, 2000) (emphasis added).

325 GUIDANCE/Q\&AS, supra note 37 (2001).

326 See, e.g., 45 C.F.R. $\S \S 164.506(\mathrm{~b})(3), 164.506(\mathrm{~b})(4), 164.508(\mathrm{~b})(1)(\mathrm{ii}), 164.508(\mathrm{~b})(3)$

327 45 C.F.R. $\$ \$ 164.506(\mathrm{c}), 164.508(\mathrm{c})(2)(2001)$.

32845 C.F.R. $\$ 164.506(\mathrm{c})(5)(2001)$.

32945 C.F.R. $\$ 164.508$ (c)(v) (2001).

330 Cf. Schreiber v. Physicians Ins. Co., 588 N.W.2d 26, 31-32 (Wis. 1999):

We reject the notion that the onset of a procedure categorically forecloses a patient's withdrawal of consent. To be sure, at some point in virtually every medical procedure a patient reaches a point from which there is no return. However, that point need not be arbitrarily created at the commencement of treatment. Rather it varies with the nature and circumstances of the individual procedure and continues so long as there exist alternative viable modes of medical treatment.

In this case, a cesarean delivery at all times remained a viable medical alternative to the VBAC [vaginal delivery] and ultimately that is how [the defendant] delivered [the baby]. Unlike the circuit court, we determine that since 
institutions redesign their informed consent forms to align them with PIHI disclosure provisions, we would likely see the insertion of related clauses in informed consent instruments. Beyond any specific example of a substantive change that might be incorporated into an informed consent form is the overall higher level of scrutiny that will be applied to consents and authorizations because of the required HIPAA compliance systems.

One obvious implication of this HIPAA-EDI induced reevaluation of consent and authorization instruments and processes will be the reinforcement of the view that the informed consent process is driven more by institutional health providers than by individual medical professionals. The overwhelming majority of courts which have considered the question have declined to impose upon hospitals a general duty to obtain a patient's informed consent, ${ }^{331}$ essentially refusing to extend the corporate negligence doctrine 332 to such facts. One oft-cited rationale for this position which holds that, "the hospital does not know the patient's medical history, nor the details of the particular surgery to be performed," 333 seems suspect in a corporate hospital environment dominated by all-seeing, all-knowing information systems. Even courts that have applied the general rule requiring informed consent endorse exceptions based on the institution acting as the physician's agent, ${ }^{334}$ assumption of the consent duty by the institution pursuant to federally regulated clinical investigations ${ }^{335}$ and, perhaps most telling for our present context, the hospital's failure to comply with its own internal policies and JCAHO standards. ${ }^{336}$ As has happened with Institutional Review Boards assuming consent responsibilities in human experimentation cases, 337 institutions forced to regularize and centralize their systems because of HIPAA-EDI likewise will assume more informed consentrelated duties. It seems inevitable that soon the exceptions will swallow up the general rule, and the institutional provider will become the default defendant in informed consent cases. 338

The second highly probable outcome of the intersection of informed consent and PIHI consent and authorization is an improvement in documentation and recordkeeping. In the case of both consent and authorization instruments, the healthcare entity must "document and retain" signed consents; 339 however, only in the case of

alternative viable modes of medical treatment existed, [the plaintiff] was still able to withdraw her consent to the VBAC. Having determined that [the plaintiff] had withdrawn her consent to the VBAC, we must now examine the effect, if any, of that withdrawal. The [plaintiffs] contend that her withdrawal both removed [the defendant's] authority to continue with the VBAC and obligated him to conduct another informed consent discussion. We agree.

331 See, e.g., Wells v. Storey, 792 So. 2 d 1034, 1044 (Ala. 1999); Bryant v. HCA Health Servs., 15 S.W.3d 804, 807 (Tenn. 2000). See also Giese v. Stice, 567 N.W.2d 156, 162-65 (Neb. 1997) (discussing how other courts have addressed the issue).

332 The doctrine is based on Darling v. Charleston Cmty. Mem'l Hosp., 211 N.E.2d 253 (III. 1965) and its progeny.

333 Krane v. St. Anthony Hosp. Sys., 738 P.2d 75, 77 (Colo. App. 1987).

334 See, e.g., Cross v. Trapp, 294 S.E.2d 446, 459 (W. Va. 1982) (holding that absent agency relationship with physician, hospital had no duty to obtain patient's informed consent to surgery).

335 See, e.g., Kus v. Sherman Hosp., 644 N.E.2d 1214, 1214 (Ill. App. Ct. 1995); Friter v. Iolab Corp., 607 A.2d 1111,1113 (Pa. Super. Ct. 1992).

336 Butler v. S. Fulton Med. Ctr., 452 S.E.2d 768, 772 (Ga. Ct. App. 1994).

337 See generally 46 C.F.R. $\$ \S 46.101-46.124$ (2001) and 21 C.F.R. $\$ \$ 56.101-56.124(200 \mathrm{i})$ for the obligations of institutional review boards supervising human experimentation.

338 Recall the discussion above as to institutional liability generally, supra text accompanying note 240 .

33945 C.F.R. $\S \S 164.506(b)(6), 164.508(b)(6)(2001)$. 
authorizations must the entity supply a copy to the patient. ${ }^{340}$ As discussed in Part VI, increased documentation, coupled with federally-mandated patient access to the medical record, will shift the balance towards plaintiffs in malpractice actions and in the informed consent subset.

The third major impact of PIHI on informed consent will be a function of the growth of data-mining and analytic systems leveraging the HIPAA-EDI architecture. Institutions will be increasingly able to analyze informed consent patterns and map them to, for example, physician-performance analyses and patient complaints. In the case of adverse events, the systems will lead to more robust peer-review reporting and scrutiny. Longer term, as computer surveillance systems come online, there will be a growth in proactive systems as they invoke specific, even personalized, risk disclosure content (delivered via video and online) that relates to the treatment or medication delivered to an individual patient. ${ }^{341}$

The intersection between PIHI consent and authorization and traditional informed consent risk disclosure has the potential to improve consent and patient choice by stimulating provider reforms of both the process and content of the latter. Despite this, the intersection also has potential negative effects. First, the PIHI consent-authorization dichotomy with its attendant endorsement of front-end loaded consent procedures seems to have learned little from the Hall-Wolf colloquy on the timing and nature of informed consents in the managed care setting. ${ }^{342}$ The PIHI message is that consent to disclose may be one-time, comprehensive and nonnegotiable. Leaving aside the question whether that is appropriate for treatmentrelated privacy consent, the PIHI model may well encourage providers to use a similar approach for consent to treatment risk-disclosures. ${ }^{343}$

Second, the PIHI regulations frequently emphasize process over substance, and encourage relatively pro forma instruments that presumably will increasingly be delivered in electronic format. ${ }^{344}$ At least in the case of consent to TPO, the patient may be given little option but to click "I Agree." 345 Rosoff has noted the efficiency, cost-saving, comprehensiveness and self-documenting features of computer-mediated informed consent models, which he refers to as computer-based patient education devices. ${ }^{346}$ While he speculates that "use of cutting-edge technology to educate patients could bring us closer to the goal of having doctor and patient collaborate as

34045 C.F.R. \& 164.508(d)(2) (2001).

341 See generally Arnold J. Rosoff, informed Consent in the Electronic Age, 25 AM. J.L. \& MED. 367 (1999) (discussing how technology is impacting doctor-patient relations).

342 See Mark A. Hall, A Theory of Economic Informed Consent, 31 GA. L. REV. 511 (1997); Susan M. Wolf, Toward a Systemic Theory of Informed Consent in Managed Care, 35 Hous. L. REV. $1631(1999)$

343 Cf. Wolf, supra note 342 , at 1639.

A systemic theory of informed consent must place treatment decisions in a broader framework. Questions of disclosure and consent arise at a number of points: when a worker takes a job offering a certain health care package, when the worker selects or reselects among health plans and enrolls in one, when the subscriber then chooses a primary care physician or clinic, and finally, when the patient consents to treatment. To reduce the informed consent problem to the question of what should happen at the last of these points fails to recognize the profoundly systemic nature of the problem of information transfer and consent.

344 "The covered entity may choose to obtain and store consents in paper or electronic form, provided that the consent meets all of the requirements under the Privacy Rule, including that it be signed by the individual. Paper is not required." GUIDANCE/Q\&AS, supra note 37.

345 See supra text accompanying notes 264-268.

346 Rosoff, supra note 341 , at 368. 
near-equals on the patient's health care," 347 Rosoff also reminds us that "there is a tendency, whenever a transaction is routinized and reduced to a ritual, for the ritual to stifle the dynamic human interaction. Even assuming that the requisite information is conveyed to the patient in a complete and understandable manner, some human interaction of the social, relational quality of the encounter may be lost." 348

Stated somewhat differently, true informed "choice" suggests a movement from professional autonomy to patient autonomy or, more positively, to sharing data and a trusting dialog. Pro forma, technologically-mediated mechanistic "consent" could, however, herald an unfortunate increase in both professional and personal dependence, overtaken by a somewhat Orwellian institutional autonomy. In that scenario, patients increasingly will look to outside sources such as Internet advice sites and infomediaries for the rich data that they require prior to making a choice and giving consent.

\section{E. CONSENT TO TECHNOLOGICALLY-MEDIATED HEALTHCARE}

The previous section examined technologically-mediated consent to traditional care and treatment. But what if it is the healthcare itself that is to be delivered via technology?349 Several states now mandate specific, additional consent in such cases. ${ }^{350}$ For example, a California statute requires an additional consent for telemedicine, holding the "health care practitioner who has ultimate authority over the care or primary diagnosis of the patient" responsible for providing verbal and written notice that:

(1) The patient or the patient's legal representative retains the option to withhold or withdraw consent at any time without affecting the right to future care or treatment nor risking the loss or withdrawal of any program benefits to which the patient or the patient's legal representative would otherwise be entitled.

(2) A description of the potential risks, consequences, and benefits of telemedicine.

(3) All existing confidentiality protections apply.

(4) All existing laws regarding patient access to medical information and copies of medical records apply.

(5) Dissemination of any patient identifiable images or information from the telemedicine interaction to researchers or other entities shall not occur without the consent of the patient. ${ }^{351}$

These statutes, focusing on the primary physician operating within the jurisdiction, tend to duck many of the issues presented in cases upon which multiple physicians are consulting. For example, the California statute imposes a duty on the primary (presumably originating) physician to disclose telemedicine risks. Yet, the

347 Id. at 384

348 Id.

349 See generally Judith F. Daar \& Spencer Koerner, Telemedicine: Legal and Practical Implications, 19 WHITTIER L. REV. 3 (1997) (providing a brief history of the development of telemedicine, as well as a discussion of its current and potential future uses). See also Jeffrey $\mathrm{L}$. Rensberger, Choice of Law, Medical Malpractice, and Telemedicine: The Present Diagnosis with a Prescription for the Future, 55 U. MIAMI L. REV. 31 (2000).

350 See, e.g., ARIZ. REV. STAT. \$36-3602(A) (2000). See also KY. REV. STAT. ANN. \$311.5975 (2000); NEB. ReV. STAT. $\S 71-8505$ (2000); OKLA. StAT. ANN. tit. 36, $\S 6804$ (West 1999).

351 CAL. Bus. \& Prof. CODE $\$ 2290.5$ (c) (West 2001). 
statute does not preclude a common law informed consent duty being imposed on the remote physician, nor does it necessarily follow that the originating physician remains responsible for disclosure of non-telemedicine specific risks. As a general rule, a remote physician does not have a duty to provide informed consent where she has no established relationship with the patient, but rather a consulting one with the patient's primary physician. ${ }^{352}$ Equally, an originating physician who has referred on the patient but is not involved in subsequent treatment will generally not face exposure to informed consent liability. ${ }^{353}$ One New York case summed up the multiple physician scenarios as follows:

A patient's personal physician bears the responsibility to assure the welfare of his patient in all phases of his treatment. Such treatment must, of necessity, include diagnosis and the prescription of a course of treatment by others, such as specialists. To the degree that the physician provides such treatment directly, he obviously bears a duty to advise his patients of the risk. Further, if he refers his patient to another physician and retains a degree of participation, by way of control, consultation or otherwise, his responsibility continues to properly advise his patients with respect to the treatment to be performed by the referred physician. ... On the same basis, once the patient is referred to another physician for treatment, the second physician also has a duty to inform the patient. ${ }^{354}$

In purely online physician-patient relationships, it will be natural for providers to build automated consent mechanisms. If mechanistic consent rather than dialog and choice become the norm, the growing temptation will be to provide voluminous online risk data (patient-incurred sorting costs notwithstanding) accompanied by a simple "I Agree/Disagree" "consent." This scenario has been playing out in general B2C ecommerce, with online vendors stocking their sites with highly favorable terms and conditions of use, including carefully chosen choice of forum or arbitration clauses and suspect privacy statements. ${ }^{355}$ In the case of hard goods ordered online, the actual terms of the contract are conditions subsequent that "arrive" with the order. Seeing a similarity to the issue raised by software licenses literally hidden within shrink-wrap, ${ }^{356}$ courts initially approved of such "click-wrap" agreements. ${ }^{357}$ Recent

352 O'Neal v. Hammer, 953 P.2d 561, 568 (Haw. 1998):

Accordingly, we hold that a consulting physician does not owe a duty to the patient to warn of the inherent risks of a proposed treatment or surgery. A physician tendering a second opinion, on the other hand, has an obligation to inform the patient of the nature of the proposed ireatment or surgery, its risks, and alternatives.

353 See, e.g., Halley v. Birbiglia, 458 N.E.2d 710, 715 (Mass. 1983) (holding that physician could not be held liable under informed consent doctrine for injuries sustained by infant where physician was not the admitting or attending physician, was not the physician who formally ordered the arteriogram and was not one of the medical personnel who spoke with the infant's parents and assured them of safety of test).

354 Prooth v. Wallsh, 432 N.Y.S.2d 663, 665 (N.Y. Sup. Ct. 1980) (citations omitted).

355 See generally Margaret J. Radin, Humans, Computers, and Binding Commitment, 75 IND. L.J. 1125, 1152 (2000) (discussing the effect of new types of contracts on our understanding of contractual commitment and on the law that determines which commitments are binding).

356 See, e.g., ProCD, Inc. v. Zeidenberg, 86 F.3d 1447 (7th Cir. 1996).

357 See, e.g., Caspi v. Microsoft Network, L.L.C., 732 A.2d 528 (N.J. Super. Ct. 1999). See also Hotmail Corp. v. Van Money Pie, Inc., No. C98-20064 JW, C-98 JW PVT ENE, 1998 U.S. Dist. LEXIS 10729, *1 (N.D. Cal. Aug 16, 1998); In re RealNetworks, Inc. Privacy Litigation, 2000 U.S. 
opinions, however, have exhibited more skepticism. ${ }^{358}$ A recent United States District Court, while not necessarily opposed to click-wrap assent, did hold that a "browse-wrap" agreement-browsing or downloading from a site containing terms of use that were never specifically brought to the consumer's attention or assented towas unenforceable. ${ }^{359}$

State telemedicine consent statutes might appear to be a step in the right direction by calling for meaningful disclosure of additional risks that the online treatment might involve. These provisions, however, are more closely tied to growing state interests in regulating online care due to fears of unauthorized practice and medical board disciplinary proceedings. ${ }^{360}$ They tend neither to address the issue of pure eHealth interactions, where there was no in-state originating physician-primarily because such interactions are viewed as suspect under state licensure statutes-nor to detail the content or substance of an informed consent to technologically-mediated care.

As noted above, the California statutory mandate is to disclose a "description of the potential risks, consequences, and benefits of telemedicine." 361 That mandate merely begs the question as to the risks of either traditional telemedicine or more advariced eHealth encounters. Spielberg has argued that physicians should discuss the ramifications of communicating electronically with patients and obtain relevant informed consent to the technological mediation. ${ }^{362}$ Such informed consent presumably would involve notifying the patient that email communications are not intrinsically secure. Patients should be warned that "operator error" frequently could lead to emails being unexpectedly forwarded, for example-not that such errors would be tolerated legally. Furthermore, the American Medical Informatics Association (AMIA) has cogently argued that the informed consent mechanism also should "[p]rovide instructions for when and how to escalate to phone calls and office visits" and "[d]escribe security mechanisms in place." 363 This latter issue is perhaps the most pressing issue to resolve in setting the legal standard. ${ }^{364}$

Dist. LEXIS 0584, at *! (N.D. Ill. May 11,2000 ).

358 See, e.g., America Online, Inc., v. Superior Court of Alameda County, 108 Cal. Rptr. $2 d 699$ (Cal. Ct. App. 2001); Willianns v. America Online, Inc., No. 00-0962, 2001 Mass. Super. LEXIS 11, at *1 (Mass. Sup. Feb. 8, 2001).

359 Netscape argues that the mere act of downloading indicates assent. However, downloading is hardly an unambiguous indication of assent. The primary purpose of downloading is to obtain a product, not to assent to an agreement. In contrast, clicking on an icon stating "I assent" has no meaning or purpose other than to indicate such assent. Netscape's failure to require users of SmartDownload to indicate assent to its license as a precondition to downloading and using its software is fatal to its argument that a contract has been formed.

Specht v. Netscape Communications. Corp., 150 F. Supp. 2d 585, 589 (2001).

360 See generally Ross D. Silverman, Regulating Medical Practice in the Cyber Age: Issues and Challenges for State Medical Boards, 26 AM. J.L. \& MED. 255 (2000) (examining the effect computers and the Internet have on the ability of state medical boards to regulate the practice of medicine, and the responses at the state and federal level to these technological developments).

361 CAL. BUS. \& PROF. CODE $\S 2290.5$ (c) (West 2001).

362 Alissa R. Spielberg, On Call and Online: Sociohistorical, Legal, and Ethical Implications of E-mail for the Patient-Physician Relationship, 280 JAMA 1353, 1353 (1998).

363 Beverly Kane \& Daniel Z. Sands, Guidelines for the Clinical Use of Electronic Mail with Patients, 5 J. AM. MED. INFORMATICS ASS'N 104, 106 (1998).

364 Indeed, there is a growing consensus that regular, unsecured email should not be used for anything but the most routine of physician-patient communications. See Press Release, MEDEM, "Avoid Standard Un-Secure E-mail for Online Communications with Patients, "Says Nation's Leading Medical Societies and the AMA, Top Malpractice Carriers and Medem Groups, Apr. 30, 2001, available at http://www.medem.com/Corporate/press. 
In many ways, therefore, the PIHI consent and disclosure requirements do little but reflect the problems facing modern informed consent. Is it really about mechanistic consent, or does it truly stimulate dialog, trust and choice? Will technologically-mediated care result in less meaningful physician-patient interaction and more patient dependency on outsourced standard-form information or data furnished by third-parties? Yet, the PIHI rules also suggest some positives. Reinforcing and standardizing consent procedures, which will frequently share space in compound documents that attract considerable and continual compliance-based scrutiny, will sharpen the overall process, and an information architecture that makes data collecting, analysis and peer-review more likely, are positive indications for the future of both the doctrine and its operational aspects.

\section{MALPRACTICE PROCESS IMPLICATIONS OF NEW PRIVACY AND SECURITY REGIMES}

This section will concentrate on some of the most practical ramifications of the new privacy and security protections applied to PHI, examining how the patient medical record will be protected and expanded by federal and, to an extent state law, and the effect of this new records paradigm on malpractice litigation. It is likely the HIPAA-EDI structure, its privacy and security rules and state-based fellow travelers, will lead to increased error reporting, especially to patients, and that this will reduce the false negatives currently seen in medical malpractice litigation. Medical malpractice plaintiffs will find themselves in a much more favorable position following the various regulatory and statutory reforms and will be able to exploit some of the new protections for litigation purposes. In this context, this section suggests that the existence of a comprehensive, secure patient record will assist plaintiffs in the preparation and trial of their cases, in large part because of legally guaranteed rights of access to and correction of their records. Finally, a comprehensive patient record will permit plaintiffs to identify additional defendants and suggest additional theories of the case.

The overall thesis of increased malpractice-related risk reallocation is somewhat dependent on three assumptions. First is that in our current system, false negatives both exist and considerably outnumber false positive results. In general, these false negatives occur when deserving plaintiffs lose and false positives occur when undeserving plaintiffs win. False negatives are caused by either by a failure to correlate a bad result with possible malpractice (i.e., an undiscovered adverse event or an adverse event uncorrelated to medical error) or a failure of factual proof (e.g., plaintiff failing to prove that defendant made a particular statement, that a particular medical intervention occurred prior to a symptom appearing or that a medication was given in a particular dosage). ${ }^{365}$ This assumption finds sustenance in the findings of false negatives in the Harvard Study discussed above. ${ }^{366}$

Second, this argument assumes that HIPAA-EDI and other legal, economic and technological forces will lead healthcare institutions and individual physicians to adopt longitudinal CPRs and that these records will be comprehensive and linked

365 A third species of false negative may be caused by a failure in the plaintiff's substantive case, such as a failure in expert testimony to prove that the defendant failed to comply with professional standards. This is less of a system error and generally will be remedied by allowing the plaintiff more latitude in proving negligence, such as by the utilization of practice guidelines. See supra text accompanying note 208.

366 See sources cited supra note 94. 
with external (e.g., non-employee physician) records relating to the patient. ${ }^{367}$

Third, it is axiomatic that the plaintiff usually will benefit from any increase in access to defendant-generated information both prior to and during trial. Not only does this seem to be intuitively accurate, but may also be proven by examining wellknown tort law correlates. For example, in fact-patterns where courts have decided to shift the risk reallocation model more in the favor of plaintiffs, they consistently impose explanatory or exculpatory burdens on defendants who they consider to have the best or cheaper information about what actually occurred. ${ }^{368}$ This has played out in medical malpractice "conspiracy of silence" type cases where the court has applied res ips a loquitur, ${ }^{369}$ pharmaceutical market-share cases ${ }^{370}$ and, in a few jurisdictions, strict products liability design defect cases. ${ }^{371}$ Obviously, cases will arise where a CPR entry will absolve a physician or institution from malpractice liability and therefore avoid a false positive. Equally, computer surveillance systems, at least in their infancy, may themselves generate some false positives. ${ }^{372}$ Overall, however, plaintiffs will benefit from increased and increasingly more robust data.

367 See generally Christopher D. Mount et al, An Integrated Electronic Health Record and Information System for Australia?, 172 MED. J. AUSTL. 25 (2000) (contending that an integrated health record and information system would provide benefits for clinicians and patients through better clinical care, and for the healthcare system through better data for policy development and resource allocation).

368 Terry, supra note 188 , at 723.

369 See, e.g., Ybarra v. Spanga:d, 154 P.2d 687,691 (Cal. 1944) (holding res ipsa charge proper despite plaintiff's inability, due to anesthesia, to specify what instrumentality, under exclusive control of which defendant, caused the injury). For a recent summary of jurisdictional attitudes towards the application of res ipsa loquilur in medical malpractice cases, particularly those requiring expert testimony as to the standard of care, see Seavers v. Methodist Med. Ctr., 9 S.W.3d 86, 93-95 (Tenn. 1999).

370 See, e.g., Sindell v. Abbott Labs, 607 P.2d 924, 937 (Cal. 1980) (finding that pharmaceutical manufacturers composing a "substantial percentage" of the drug market could each be liable for an amount proportionate to its market share, absent proof that it could not have produced the DES consumed by plaintiff's mother). See also Summers v. Tice, 199 P.2d 1, 3-4 (Cal. 1948) (holding that the exculpatory burden applied where plaintiff could not prove which of two hunters' bullets had injured him).

371 Barker v. Lull Eng'g Co., 573 P.2d 443, 455 (Cal. 1978) (adopting a risk-benefit analysis test for strict products liability design defect cases with the burden of proof allocated to defendant manufacturer).

The allocation of such burden is particularly significant in this context inasmuch as this court's product liability decisions, from Greenman to Cronin, have repeatedly emphasized that one of the principal purposes behind the strict product liability doctrine is to relieve an injured plaintiff of many of the onerous evidentiary burdens inherent in a negligence cause of action. Because most of the evidentiary matters which may be relevant to the determination of the adequacy of a product's design under the "risk-benefit" standard e. g., the feasibility and cost of alternative designs are similar to issues typically presented in a negligent design case and involve technical matters peculiarly within the knowledge of the manufacturer, we conclude that once the plaintiff makes a prima facie showing that the injury was proximately caused by the product's design, the burden should appropriately shift to the defendant to prove, in light of the relevant factors, that the product is not defective. Moreover, inasmuch as this conclusion flows from our determination that the fundamental public policies embraced in Greenman dictate that a manufacturer who seeks to escape liability for an injury proximately caused by its product's design on a risk- benefit theory should bear the burden of persuading the trier of fact that its product should not be judged defective, the defendant's burden is one affecting the burden of proof, rather than simply the burden of producing evidence.

Id. See generally Terry, supra note 188 , at $726-30$

372 See Luiza A.B. Camacho \& Haya R. Rubin, Assessment of the Validity and Reliability of Three Systems of Medical Record Screening for Quality of Care Assessment, 36 MED. CARE 748, 748 (1998). 


\title{
A. MALPRACTICE LiTIGATION AND THE CPR
}

The written medical record is of utmost importance in medical malpractice litigation. ${ }^{373}$ It is the initial "script" of the case, delineating the timeline and parties involved in patient care and dictating many of the discovery requests that will follow. Thereafter, as a perceived island of verity surrounded by accusation, argument and conflicting testimony, the tangible record has a powerful impact on juries. The traditional paper patient record, however, lacks integrity. Medical records are not always complete or centralized and reported cases tell us about records that have "mysteriously vanished," 374 altered so as to be unreadable 375 or altered with the express intent of avoiding malpractice liability. ${ }^{376}$ Ten years ago the IOM described the CPR of the future as follows:

\begin{abstract}
[A]s an electronic patient record that resides in a system specifically designed to support users through availability of complete and accurate data, practitioner reminders and alerts, clinical decision support systems, links to bodies of medical knowledge, and other aids. This definition encompasses a broader view of the patient record than is current today, moving from a location or device for keeping track of patient care events to a resource with much enhanced utility in patient care (including the ability to provide an accurate longitudinal account of care), in management of the health care system, and in extension of knowledge. 377
\end{abstract}

For litigators, therefore, the CPR compares most favorably to its paper antecedent. A comprehensive, time-stamped record coupled with the JCAHOmandated duty to disclose adverse events will constitute good evidence of "fraudulent concealment" so as to resist a statute of limitations defense. 378 The CPR is "whiteout" proof, as any alterations to the record will be logged and previous versions will be available for comparison-subject to the institution's document retention policy. ${ }^{379}$ Even more importantly, the modern CPR will be complete and

373 See Am. HEAlth Info. MGMt. ASs'N, Practice Brief: Definition of the Health Record for Legal Purposes, at http://www.ahima.org/journal/pb/01.10.2.html (last visited Nov. 20, 2001). See generally Robert Gray Palmer, Altered and 'Lost' Medical Records, 35 TRIAL 31 (1989) (contending that evidence of spoliation of records in medical negligence actions can strengthen a client's case).

374 Moskovitz v. Mt. Sinai Med. Ctr., 635 N.E.2d 331, 344 (1994) (finding evidence regarding physician's alteration of patient's records supported award of punitive damages).

375 Gordon v. Willis Knighton Med. Ctr., 661 So. 2d 991, 993 (La. Ct. App. 1995) (noting that while the entry in the hospital's emergency room records indicatc when the patient arrived, the entry had been altered in such a manner that no one could determine the original entry).

376 Dimora v. Cleveland Clinic Found., 683 N.E.2d 1175, 1182 (1996) (holding that evidence submitted was sufficient to raise a factual question requiring determination by a jury as to whether progress and discharge notes were falsified or inaccurately reported to avoid liability for medical malpractice). See also Robinson v. Singing River Hosp. Sys., 732 So. 2d 204 (Miss. 1999). See generally Lynn Wilson Marks, Medical Malpractice: Case Management and Other Guidelines, $7 \mathrm{~J}$. FORENSIC DOCUMENT EXAM. 11 (1994); Robert L. Prosser, Alteration of Medical Records Submitted for Medicolegal Review, 267 JAMA, 2630, 2630 (1992) ("Issues related to alterations of medical records have surfaced in four of the 10 medicolegal cases 1 have reviewed in the last 12 months.").

377 COMPUTER-BASED PATIENT RECORD, supra note 137, at 2-3.

378 See, e.g., Shadrick v. Coker, 963 S.W.2d 726, 731 (Tenn. 1998). See also Barry R. Furrow, Doctors' Dirty Little Secrets: The Dark Side of Medical Privacy, 37 WASHBURN L.J. 283 (1998) (discussing physician duties regarding patient privacy rights).

379 See generally Kimberly D. Richard, Note and Comment, Electronic Evidence: To Produce 
comprehensive, built from self-documenting inputs such as POE ${ }^{380}$ and barcodebased systems. It will record and time-stamp all interactions with the patient and log the identity of involved careproviders and the information they had available (e.g., the dispensing of a contraindicated drug by another care provider) at an exact point in time.

\section{B. HIPAA-EDI PRIVACY AND SECURITY FOR THE CPR}

If the CPR and related parts of the modern IT-driven hospital or physician office database and expert systems suggest the promise of litigating from a comprehensive, all-knowing record, then the HIPAA-EDI Security NPRM should guarantee the data's integrity and make objections to its introduction into evidence extremely difficult. ${ }^{381}$

The Security NPRM requirements are divided into three broad areas: (1) administrative procedures, such as policies, plans, audit and training; ${ }^{382}$ (2) physical security, such as access control and disaster recovery systems;383 and, (3) technical security, such as authentication and encryption. ${ }^{384}$ Not surprisingly, many of these requirements concentrate on dangers posed by external forces such as hackers and viral infection; 385 however, there are also specific rules which make a CPR operating under HIPAA-EDI a more potent courtroom weapon. For example, a data backup plan, ${ }^{386}$ strong authorization policies ${ }^{387}$ and access controls ${ }^{388}$ will all guarantee the integrity of a record required for litigation. Furthermore, the systems must use data authentication and user identification, ${ }^{389}$ and establish processes for tracking and auditing system access. 390 Not only will the CPR be secure, but precise information will be available as to who interacted with it, and when. Care provider interaction with patient documents will also be authenticated and audited via the use of digital signatures, ${ }^{391}$ which HIPAA-EDI will include within its regulatory system. ${ }^{392}$

While the Security NPRM guarantees the integrity of the CPR, the PIHI rules may have some serious litigation implications of their own. Specifically, some fascinating questions arise concerning the possible effect of the access and accounting rules contained within the privacy regulation.

or Not to Produce. That is the Question, 21 WHITTIER L. REV. 463 (1999) (examining the impact new technology has on clients, attorneys, courts and the legal system in general).

380 See supra text accompanying note 125

381 The CPR is hearsay under Federal Rule of Evidence 801, but admissible under the business records exception in Rule 803(6), subject to compliance with conditions therein. See, e.g., Welsh v. Galen of Va., Inc., 2001 WL S02123, *1 (Ky. App. May 11, 2001); Powell v. Catholic Med. Ctr., 749 A.2d 301 (N.H. 2000); Patterson v. Hutchens, 529 N.W.2d 561 (N.D. 1995).

382 Security and Electronic Signatures; Proposed Rule, 63 Fed. Reg. 43,241, 43,266 (Aug. 12, 1998) (to be codified at 45 C.F.R. § 142.308(a)).

383 Security and Electronic Signatures, Proposed Rule, 63 Fed. Reg. at 43,267.

384 Security and Electronic Signatures, Proposed Rule, 63 Fed. Reg. at 43,268.

385 See, e.g., Diane Levick, Insurers At Risk Online, Study Says, HARTFORD COURANT, Sept. 7, 2001 , at E2.

386 Security and Electronic Signatures, Proposed Rule, 63 Fed. Reg. at 43,266.

387 Security and Electronic Signatures, Proposed Rule, 63 Fed. Reg. at 43,266.

388 Security and Electronic Signatures, Proposed Rule, 63 Fed. Reg. at 43,268.

389 Security and Electronic Signatures, Proposed Rule, 63 Fed. Reg. at 43,268.

390 Security and Electronic Signatures, Proposed Rule, 63 Fed. Reg. at 43,268.

391 See, e.g., VERISIGN, Healthcare Authentication Services, at http://www.verisign.com/ enterprise/healthcare/authentication.html (last visited Nov. 10, 2001). See also AM. MED. ASs'N, AMA Internet ID: Protecting Your Identity Online, àt www.ama-assn.org/internetid (last modified Oct. 25, 2001).

392 Currently, this regulation is to be codified at 4 S C.F.R. $\$ 143.310$, but likely will be spun off into a separate rule. 
Not surprisingly, the healthcare entity may disclose most PHI to the patient herself ${ }^{393}$ and is permitted to disclose such information pursuant to legal process. ${ }^{394}$ Additionally, however, the PIHI regulation gives the patient "a right of access to inspect and obtain a copy of protected health information about the individual." 395 There are only a few discrete exceptions to this rule, such as for a psychotherapist's impressionistic "process notes." 396 Importantly, the right of access is limited to "protected health information about the individual in a designated record set," 397 and a provider will be able to keep peer-review and related information out of a "designated record set." 398

Although the provider may charge a reasonable fee ${ }^{399}$ and demand that the request is in writing, ${ }^{400}$ ultimately, the provider has little choice but to comply in a timely fashion 401 with a patient's request. While not an example of self-executing adverse error reporting - in contrast to, for example, JCAHO mandated disclosure to the patient ${ }^{402}$ the plaintiff who has suffered an adverse event is likely to use this PIHI right of access as the first step in an inquiry as to exactly what went wrong and thereafter, whether there had been malpractice. 403

As the potential for litigation over, for example, an adverse event becomes clearer, a plaintiff's attorney, working through the patient's PIHI rights, may also be able to exploit other provisions in the regulations prior to any formal discovery. The accounting or audit provisions 404 will be of only limited use because they exempt TPO disclosures. ${ }^{405}$ Notwithstanding, in some cases a plaintiff's attorney might find

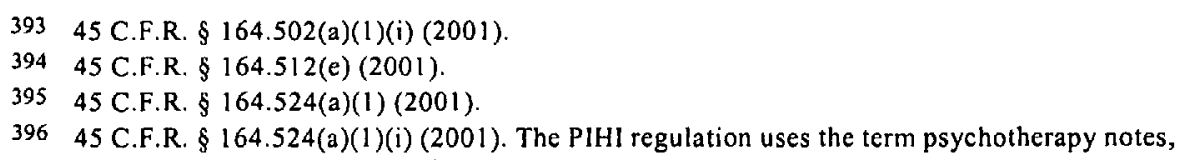

396 45 C.F.R. $\$ 164.524(\mathrm{a})(1)(\mathrm{i})(2001)$. The PIHI regulation uses the term psychotherapy notes, as defined in 45 C.F.R. $\$ 164.501$ (2001).

397 45 C.F.R. $\$ 164.524(\mathrm{a})(1)(2001)$.

39845 C.F.R. $\$ 164.501$ defines the "designated record set" as:

A group of records maintained by or for a covered entity that is:

(i) The medical records and billing records about individuals maintained by or for a covered health care provider;

(ii) The enrollment, payment, claims adjudication, and case or medical management record systems maintained by or for a health plan; or.

(iii) Used, in whole or in part, by or for the covered entity to make decisions about individuals.

Presumably the only (thin) argument that could be raised by the individual is the whether the peerreview material could be included under (iii). Presumably, a provider could be at risk it fails to segregate out its records as suggested by the designated set language.

39945 C.F.R. $\$ 164.524$ (c)(4) (2001). Undefined in PIHI, the reasonable fee under the Montana health privacy statute is addressed as follows:

A reasonable fee for providing health care information may not exceed 50 cents for each page for a paper copy or photocopy. A reasonable fee may include an administrative fee that may not exceed $\$ 15$ for searching and handling recorded health care information.

MONT. CODE ANN. $\$ 50-16-540$ (2000).

$400 \quad 45$ C.F.R. $\$ 164.524(\mathrm{~b})(1)(2001)$.

401 See, e.g., 45 C.F.R. $\S 164.524$ (c)(3) (2001).

402 See supra text accompanying note 174.

403 The window will close to an extent as litigation looms closer because 45 C.F.R. $\$$ $164.528(1)$ (ii) allows the provider to deny a request to access "Information compiled in reasonable anticipation of, or for use in, a civil, criminal, or administrative action or proceeding."

40445 C.F.R. $\$ 164.528$ (2001) ("An individual has a right to receive an accounting of disclosures of protected health information made by a covered entity in the six years prior to the date on which the accounting is requested.").

40545 C.F.R. $\$ 164.528(a)(1)(i)(2001)$. 
value in finding out who else has been looking at the plaintiff's records.

Perhaps of more value in the context of contemplated litigation is the amendment provision whereby "[a]n individual has the right to have a covered entity amend protected health information." 406 Given the power of the medical record when placed in front of a jury, the plaintiff may well have an interest in having "her story" portrayed to better reinforce her theory of liability. The "covered entity may deny an individual's request for amendment, if it determines that the protected health information or record that is the subject of the request ... [i]s accurate and complete." 407 Yet, outside of the context of formally initiated litigation, the provider may not see the purpose of the patient's proposed amendment. Even if the request is denied, a plaintiff's attorney may gather useful intelligence from the required reason for denial.408 The patient also has the right to add a "Statement of disagreement" to the record. 409

\section{State Rules With Process Implications}

Several states have asserted their own interests in the modern medical record. For example, the California legislature has determined that "every person having ultimate responsibility for decisions respecting his or her own health care also possesses a concomitant right of access to complete information respecting his or her condition and care provided."410 Similarly, the Montana legislature has opined that "patients need access to their own health care information as a matter of fairness, to enable them to make informed decisions about their health care and to correct inaccurate or incomplete information about themselves." 411

The PIHI rules do not fully preempt "more stringent" state laws relating to access to medical records 412 in cases where the state law "permits greater rights of access or amendment." 413 The 1999 Health Privacy Project State Report found that thirty-three states provide a right of access to hospital records; thirteen states provide a right of access to HMO records; and sixteen states provide a right of access to insurance records. ${ }^{414}$ As a result, provisions of state law-particularly those based on the Uniform Health-Care Information Act ${ }^{415}$ which was adopted by Montana ${ }^{416}$ and

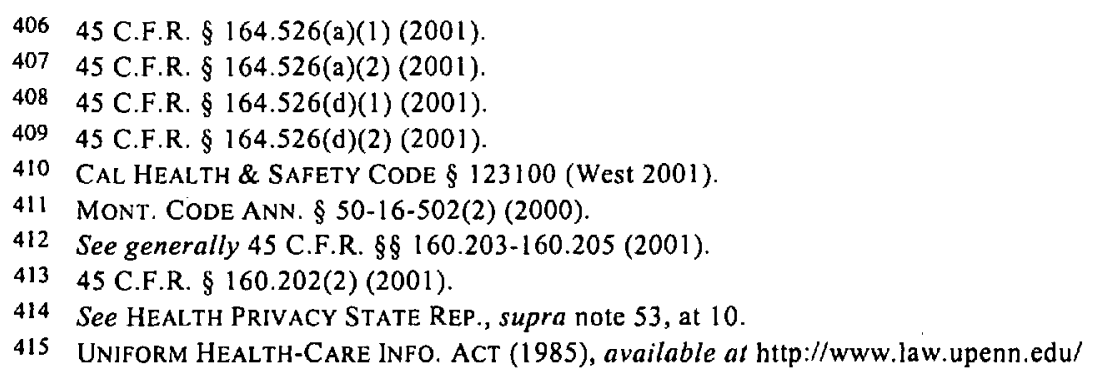
bll/ulc/fnact $99 / 1980$ s/uhcia 85 .htm. The National Conference of Commissioners on Uniform State Laws has recently released a discussion draft, PROPOSED REVISIONS OF UNIFORM HEALTH CARE INFO. ACT (2000), available at http://www.law.upenn.edu/bll/ulc/uhcia/hci0600.htm. According to the Commissioners:

The Act has been revised to reflect the explosion in information technology and changes in the practice of medicine through managed care and large multi-state providers. Moreover, the recent flurry of state legislation and proposed model acts has largely bypassed the 1985 Uniform Act, possibly because of concerns over limitations in its scope and safeguard provisions and because the language does not reflect electronic technology. The revised Act addresses those concerns by expanding coverage under the Act to persons receiving health care information in the regular course of business, by strengthening the requirements for security safeguards, and by drafting to reflect modern computer technology and electronic transmissions. 
Washington, ${ }^{417}$ or in other states that have comprehensive medical privacy laws ${ }^{418}$ may have an impact on malpractice litigation. For example, the Montana statute imposes a tighter timetable on patient requests for access to the record, 419 and the provider can be requested to explain codes used in the record. 420 Overall, however, and keeping in mind that this is an area where generalizations are difficult due to varying levels of detail and applicability, most state access laws seem to provide for conceptually similar access, amendment and accounting rules. ${ }^{421}$

\section{HIPAA-EDI EXPANDING THE CPR}

Assumptions have been made above about institutions that adopt comprehensive CPR systems, in large part driven by the HIPAA-EDI mandate, but also to facilitate compliance with other regulatory and accreditation reporting requirements. Once adopted, however, it is likely that the breadth of these systems will continue to grow, as will their potential utility for malpractice plaintiffs.

Roughly one-quarter of online physicians communicate with their patients via email.422 Increasingly, physicians are finding it an attractive medium because it is potentially rich-for example, facilitating the inclusion of URL references to other resources that the patient should consider-and it is self-documenting, in that the stored communications create their own "record" on the doctor's or her institution's computer. This latter factor, coupled with the obvious fact that it contains "individually identified health information" "transmitted by electronic media," 423 will subject a patient-physician email dialog to PIHI regulation.

Perhaps less obvious is how the CPR will swell with conversations between care provider and patient. In practice, the PIHI rules will seldom apply to purely oral communications; nor do they impose any duty to record such conversations. However, if an entity does record or transcribe a conversation, and such records are maintained and used to make decisions about the individual, then they would be swept into the path of PIHI.424 This issue is likely to cause particular difficulty as institutions exploit their new information infrastructures by migrating from traditional telephone systems to routing - not to mention monitoring and recordingtheir voice communications through existing data networks. 425 This presumably will convert transient oral communications into electronic media created or received by the provider, thereby subjecting it to PIHI.

The expanding CPR may also interest attorneys seeking to construct malpractice claims based on aggregate data. Assume that the attorney is constructing a loss-of-

\footnotetext{
Proposed ReVisions of Uniform Healti CARE INFo. ACt 2 (2000).

416 MONT. CODE ANN. $\$ \$ 50-16-501$ to 50-6-504 (2000).

417 WASH. REV. CODE $\S \S 70.02 .005$ to 70.02 .904 (2000)

418 See, e.g., CAL. CIV. CODE § 56-56.37 (West 2001); R.I. GEN. LAWS § 5-37-22 (2000); WIS.

STAT. $\S \S 146.83,610.70(3)(2001)$.

419 MONT. CODE ANN. § 50-16-541(1) (2000).

420 MONT. CODE ANN. \$ 50-16-541(2) (2000).

421 "[I]n many ways, the state laws defy summarization $\mathrm{C}$ (sic)they are detailed, specific, and intricate." HEALTH PRIVACY STATE REP., supra note 53, at 10.

422 See Press Release, AM. MED. Ass'N., AMA Survey Finds Upsurge in Physician Usage and Regard for Internet, May 9, 2001, availabie at http://www.ama-assn.org/ama/pub/category/1616.html.

42345 C.F.R. $\S 164.501$ (2001).

424 GUIDANCE/Q\&AS, supra note 37.

425 This is known as TCP/IP telephony. See generally MICROSOFT, MICROSOFT WINDOWS 2000 SERVER DOCUMENTATION: IP TELEPHONY CONCEPTS, at http://www.microsoft.com/windows2000/en/ server/help/default.asp (last visited Nov. 12, 2001).
} 
chance case $^{426}$ in which the national survival rate for the allegedly undiagnosed disease in question is $20 \%$, a statistic which would operate as the damages multiplier. Now assume that the defendant hospital has a survival rate with the disease diagnosed believed to be $40 \% .427$ The PIHI rules, in contrast to the conventional discovery arguments that plaintiffs will make-not necessarily with success-would not seem to provide a basis to compel the hospital to generate even de-identified data pertinent to survival rates. 428 Consistent with this interpretation, the California statute defines medical records subject to its patient access law as "only records pertaining to the patient requesting the records or whose representative requests the records" and not including "information given in confidence to a health care provider by a person other than another health care provider or the patient" or "information contained in aggregate form, such as indices, registers, or logs." 429

A new round of empirical studies will be required before the pro-plaintiff impact of HIPAA-EDI, related technologies and new error reporting paradigms can be conclusively demonstrated. Furthermore, malpractice attorneys, insurers and risk managers may not see all the implications of HIPAA-EDI until healthcare institutions have the next generation of CPRs up and running. The availability of comprehensive records and the growth of non-peer-review reporting, however, should inevitably lead to the identification of additional occurrences of malpractice. Coupled with the additional access and data that malpractice plaintiffs will receive courtesy of PIHI, this should lead to a significant decrease in false negatives and increase the settlement value of heretofore marginal cases.

\section{CONCLUSION}

Managed care has become the piñata of modern healthcare reform. 430 In the process, we have freighted what is little more than a somewhat flawed financing system with all the ills of modern healthcare delivery. ${ }^{431}$ Hopefully, the passage of a Patient's Bill of Rights ${ }^{432}$ will bring closure on the more excessive claims of those on both sides of the debate, and enable us to concentrate our energies on the more pressing issues of patient privacy and medical error.

The rhetoric of privacy and improved quality may not yet be as powerful as that seen in prior debates over individual rights such as the fight for patient autonomy. Neither, at first sight, does the somewhat impersonal medium of information technology appear to be a likely conduit of satisfactory reform. Indeed, nothing said

426 For a primer, see Michelle L. Truckor, Comment, The Loss of Chance Doctrine: Legal Recovery for Patients on the Edge Of Survival, 24 DAYTON L. REV. 349 (1999).

427 This percentage is still below the summary judgment standard for "more probable than not" under a conventional causation standard. See, e.g., Bell v. United States, 854 F.2d 881, 883 (6th Cir. 1988).

428 See, e.g., Shady Grove Psychiatric Group v. Md., 736 A.2d 1168, 1173 (Md. 1999) (noting that under extant Maryland law a health care provider is required to disclose a medical record to a prosecution agency pursuant to a subpoena issued in a criminal investigation, but only if the prosecution agency first proves that it has written procedures to protect the confidentiality of that record).

429 CAL. HEALTH \& SAFETY CODE $§ 123105$ (d) (West 2001).

430 See generally Robin Toner, After Patients' Rights: Vast Needs, Higher Hurdles, N.Y.TIMES, July 2, 2001, at $A 11$ (discussing the multitude of issues confronting Congress after passage of the Patient's Bill of Rights).

431 See Milt Freudenheim, A Changing World is Forcing Changes on Managed Care, N.Y. TIMES, July 2, 2001, at Al (discussing how managed care is evolving under pressure from doctors, patients, consumer advocates and employers).

432 E.g., Bipartisan Patient Protection Act, S. 1052, 107th Cong (2001). 
here should be taken to suggest that increased use of information technologies is the panacea for rectifying all medical error, ${ }^{433}$ or will not itself lead to a new raft of difficult legal and ethical issues.

Only recently has the healthcare industry signaled that it is poised to embark on an IT revolution.434 The industry's track record heretofore has not been stellar. Indeed, it has been glacial in its adoption of new technologies that have been aggressively deployed in other industries. ${ }^{435}$ Blame for such reticence may be laid at the feet of reluctant physicians ${ }^{436}$ and institutions that have been disinclined to commit to the necessary level of investment.437 HIPAA-EDI, unpleasant medicine that it is for many providers, ${ }^{438}$ is the crucial incentive that will trigger the longawaited revolution.

Health privacy and the reduction of medical error share a philosophical heartthe reaffirmation of the responsibilities of the healthcare system to individual consumers. As we develop our responses to these issues, health lawyers will begin to appreciate that the familiar triad of quality assurance, access and cost reduction share a common link in healthcare processes and technologies.

Health privacy has become politicized and no doubt a similar fate will befall attempts to legislate error reduction. Privacy regulation will continue to attract headlines and legal challenges, ${ }^{439}$ as surely as Congress 440 and the executive will

433 See, for example, recent evidence-based research commissioned by AHRQ that studied documented methods of improving patient safety and identified eleven essentially clinical measures as having the most potential impact. MAKING HEALTH CARE SAFER, supra note 126 , at v-vi.

434 See Robert McCarthy, Health Care Dragged, Clicking and Beeping, Into the Digital Age, 13 DRUG BenEFIT TRENDS 20, 25 (2001); Craig Stoltz, Welcome to the \#?!!*\&"! Future of Medicine, WASH. POST, Jan. 9, 2001, at T8; Bill Scanlon, The Net is a Prescription for Medicine, ZDNET INTERACTIVE WEEK (Mar. 19, 2001), at http://www.zdnet.com/intweek/stories/news/0,4164,2696791, $00 . \mathrm{html}$.

435' Jennifer Steinhauer, In a Health Revolution, a Hospital's Baby Steps, N.Y. TIMES, at http://www.nytimes.com/library/tech/00/10/biztech/technology/ (Oct. 25, 2000).

436 The latest AMA survey suggests some movement here. Although the proportion of physicians having a Web site has leveled off, the survey discloses significant increases in physician use of the Web for research and as a resource for patient education. Furthermore, roughly one-quarter of online physicians communicate with their patients via email. See Press Release, AM: MED. ASS'N, AMA Survey Finds Upsurge in Physician Usage and Regard for Internet, May 9, 2001, available at http://www.ama-assn.org/ama/pub/category/1616.html. See also Tyler Chin, Tech Effect: Better health Care Through Information Technology, AMA NEwS, Aug. 13, 2001, available at http://www.amaassn.org/sci-pubs/amnews/pick_01/tesa0813.htm; HARRIS INTERACTIVE, New Data Show Internet, Website and Email Usage by Physicians all Increasing, 8 HEALTH CARE NEwS, Feb. 26, 2001, available at http://www.harrisinteractive.com/news/newsletters_healthcare.asp.

437 There are, of course, exceptions. See, e.g., Assoc. Press, Digital Hospital Moves Health Care into Internet Age, USA TODAY, at http://www.usatoday.com/life/cyber/tech/2001-03-27-hospital.htm (Mar. 27, 2001); Press Release, HEALTHSOUTH, HEALTHSOUTH, Oracle to Build Groundbreaking Digital Hospital, Mar. 26, 2001, available at http://www.healthsouth.com.

438 Gartner's second quarterly survey on compliance with the regulations of the Health Insurance Portability and Accountability Act (HIPAA) completed in February 2001 , showed that only 18 percent of healthcare payer organizations and 4 percent of healthcare providers had at least begun pianning the remediation for all of their application software.

See WES RISHEL, GARTNER RESEARCH INC., THE Y2K LESSON FOR HIPAA: NAIL DOWN YOUR VENDORS EARLY 1 (2001), available at http://www3.gartner.com/1_research analysis/focus/health_fa.html.

439 See, e.g., S.C. Med. Ass'n v. HHS, D.S.C., No. C/A 3-01-2965 (D. S.C. July 16, 2001) (challenging the constitutionality of section 264 of HIPAA as violative of separation of powers). See also Mike Stobbe, SCMA Fights New Patient Information Rules, THE STATE, July 16, 2001, available at http://web.thestate.com/content/columbia/2001/07/16/local/medrules 16.htm; Press Release, ASs'N Am. Physicians ANd Surgeons, AAPS Doctors Sue to Stop HHS Privacy Regs/Release Survey of Doctors on HIPAA Rules, July 31, 2001, available at http://www.aapsonline.org. 
engage in endless tweaking of the PIHI regulations ${ }^{441}$ and the states will append their own rules. Notwithstanding, the privacy regulations and all the other EDI-associated HIPAA regulations will persevere as crucial collaborators in the reduction of medical error and the reshaping of medical malpractice law. Linked by common technologies and consistent philosophies, the protection of patient privacy and the reduction of medical error will be the dominant concerns for the next decade of healthcare reform and will stimulate many of the structural changes we will experience, particularly the increased use of information technologies to deliver healthcare services. In the process, medical malpractice law and litigation will undergo their own revolution, reshaped by these very technologies, processes and patient expectations.

440 See, e.g., Health Data Mgmt., Legislators Ask Thompson to Fix Privacy Rule, Provide Funds, available at http://www.healthdatamanagement.com/html/hipaa/hipaa.cfm (July 19, 2001) (discussing letters to Secretary Thompson from 165 House and fifteen Senate members urging changes to privacy rule and financial assistance for providers). See also S. 1684, 107th Cong. (2001) (providing a one year extension of the date for compliance with EDI, but not the privacy aspects of the HIPAA regulations).

441 See, e.g., GuIDANCE/Q\&As, supra note 37. Specifically, the Guidance answered the following question:

Q: What changes might you make in the final rule?

$A$ : We continue to review the input received during the recent public comment period to determine what changes are appropriate to ensure that the rule protects patient privacy as intended without harming consumers' access to care or the quality of that care.

Examples of standards in the Privacy Rule for which we will propose changes are:

- Phoned-in Prescriptions...

- Referral Appointments...

- Allowable Communications...

- Minimum Necessary Scope ....

In addition, HHS may reevaluate the Privacy Rule to ensure that parents have appropriate access to information about the health and well-being of their children....

Other changes to the Privacy Rule also may be considered as appropriate.

See also the Aug. 6, 2001 letter to DHHS Secretary Thompson from eighty-six healthcare and employer organizations urging the Secretary to "move as expeditiously as possible" to modify the privacy regulations, available at http://www. hipaadvisory com $/$ news $/ 2001 / \mathrm{hlc0806}$. htm. 
